
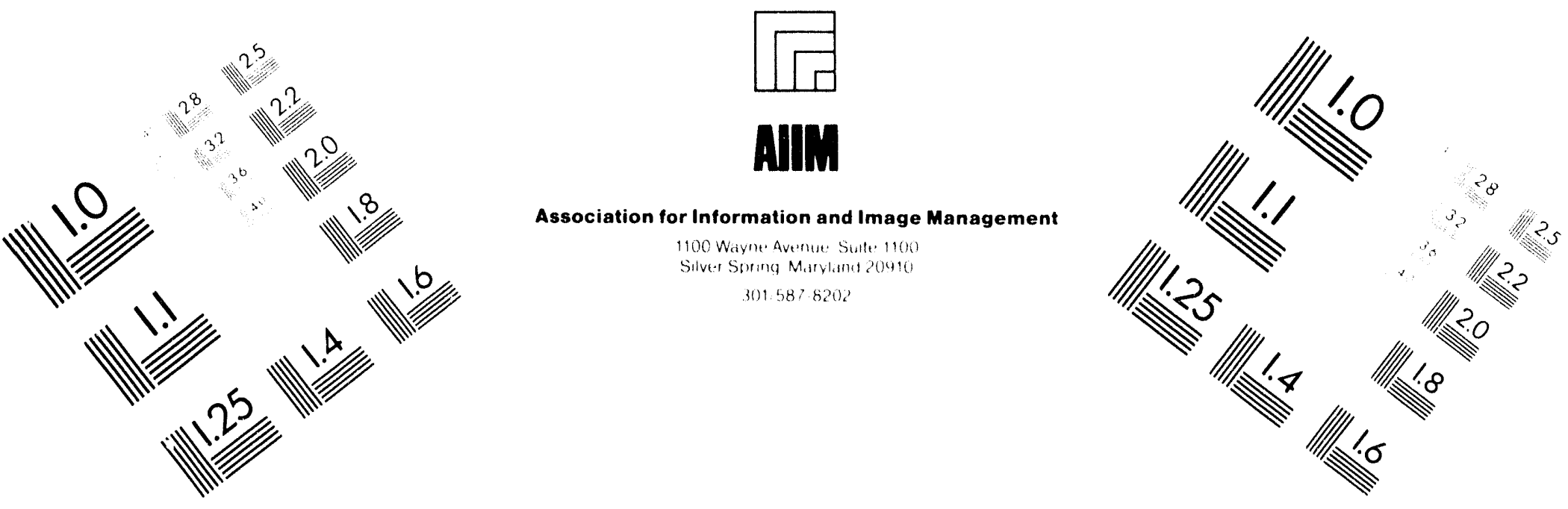

\title{
Centimeter
}

$\begin{array}{llllllllllllllll}1 & 2 & 3 & 4 & 5 & 6 & 7 & 8 & 9 & 10 & 11 & 12 & 13 & 14 & 15 & \end{array}$

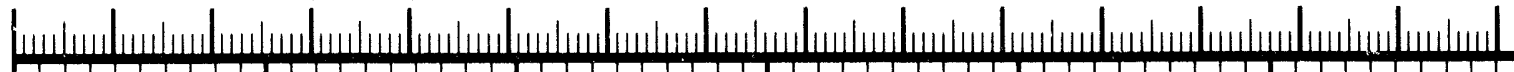

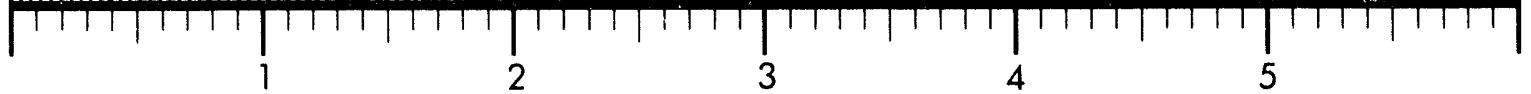
Inches
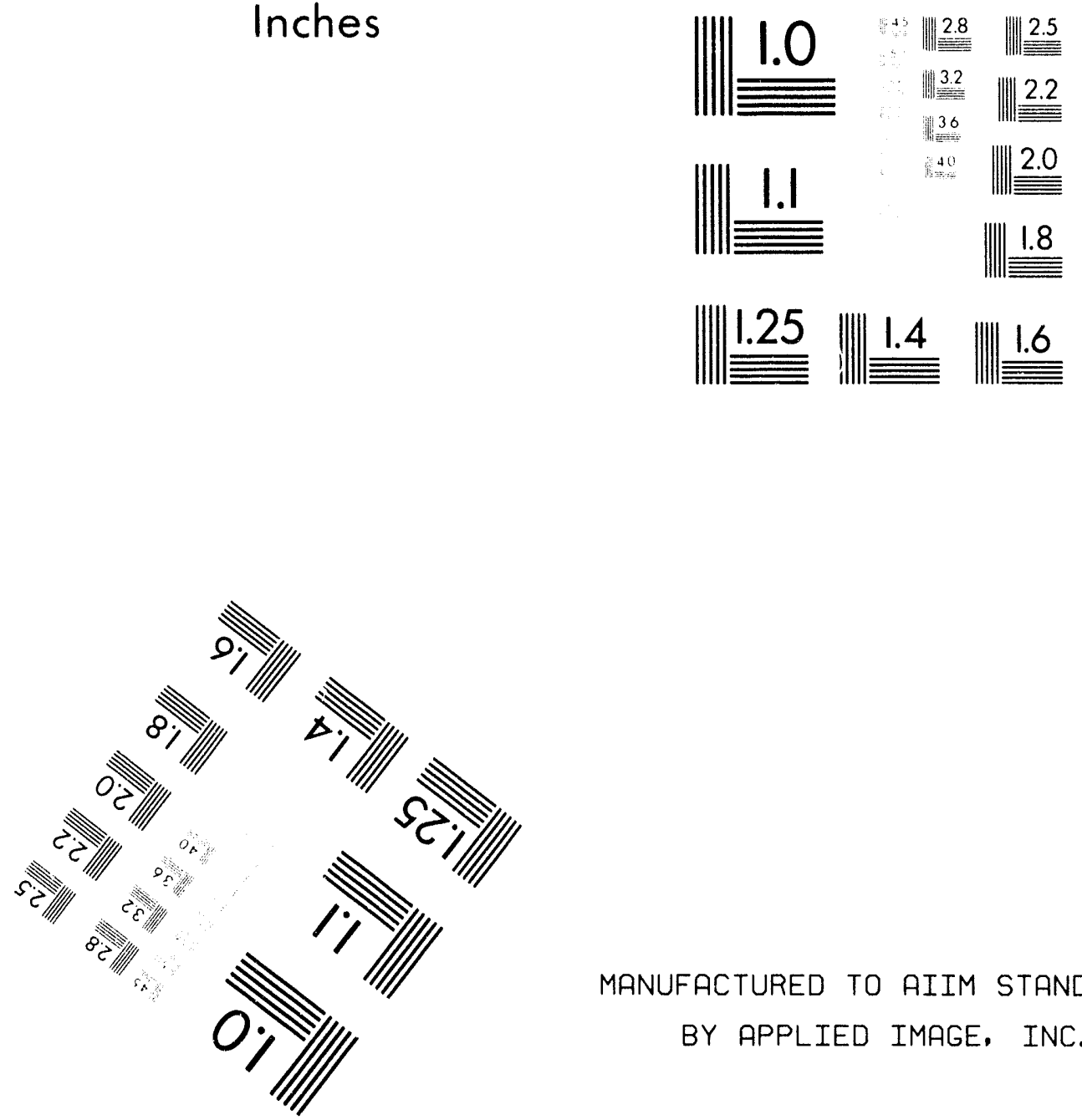

MANUFACTURED TO AIIM STANDARDS

BY APPLIED IMAGE, INC.

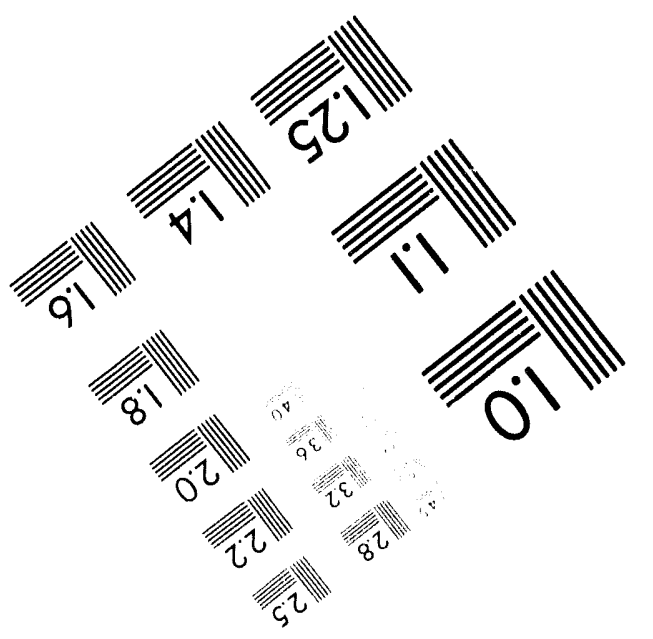



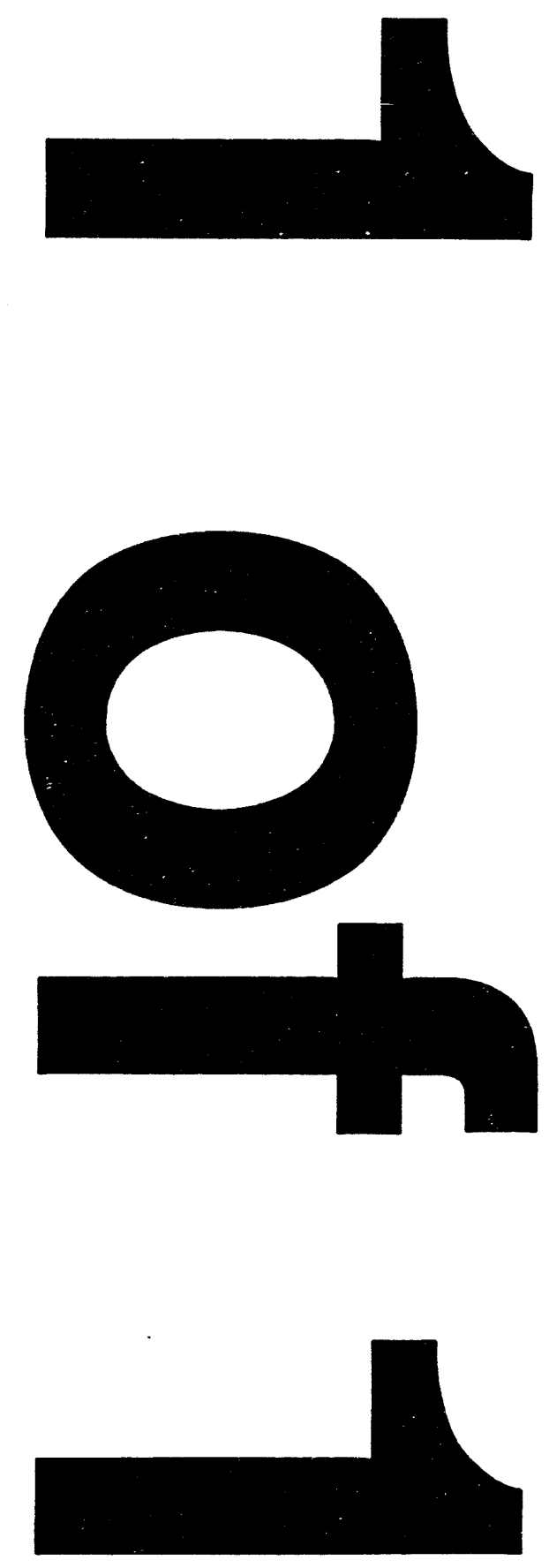


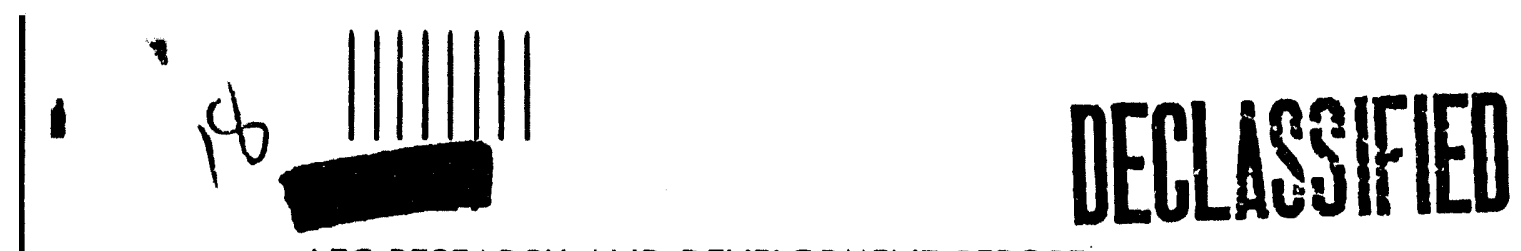

AEC RESEARCH AND DEVELOPMENT REPORT

HW-73275

COPY No. 5

\section{IRRADIATION EFFECTS \\ ON NUCLEAR fUEL ELEMENTS \\ IN THE HANFORD REACTORS}

L. T. HAGIE and

J. B. JAECH

MAY, 1962

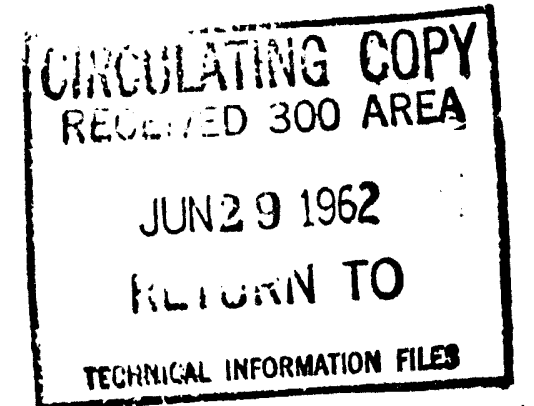

HANFORD ATOMIC PRODUCTS OPERATION RICHLAND, WASHINGTON

GENERAL (g? ELCTRIC

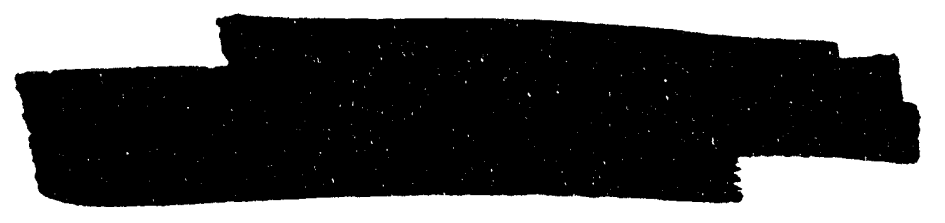

Mond

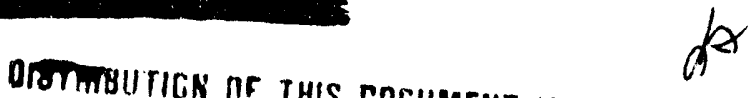

$d x$ 


\section{LEGAL NOTICE}

This report was prepared as an account of Government sponsored work. Neither the United States, nor the Commission, nor any person acting on behalf of the Commission:

A. Makes any warranty or representation, expressed or implied, with respect to the accuracy, com. pleteness, or usefulness of the information contained in this report, or that the use of any information, apparafus, method, or process disclosed in this report may not infringe privately owned rights; or

B. Assumes any liabilities with respect to the use of, or for damages resulting from the use of any information, apparatus, method, or process disclosed in this report.

As used in the above, "person acting on behalf of the Commission" includes any employee or contractor of the Commission, or employee of such contractor, to the extent that such employee or contractor of the Commission, or employee of such contractor prepares, disseminates, or provides access to, any information pursuant to his employment or contract with the Commission, or his employment with such contractor. 


\section{DEELLASSFFIED}

This document classified by B. J. Borgmier
HW -73275

C-65, Plutonium Production (M-3679, 26th Ed.)

This document consists of 54 pages. Copy No. 5 of 146 copies.

IRRADIATION EFFECTS

ON NUCLEAR FUEL ELEMENTS

IN THE HANFORD REACTORS

By

L. T. Hagie

Advance Fuel Engineering

Fuels Preparation Department

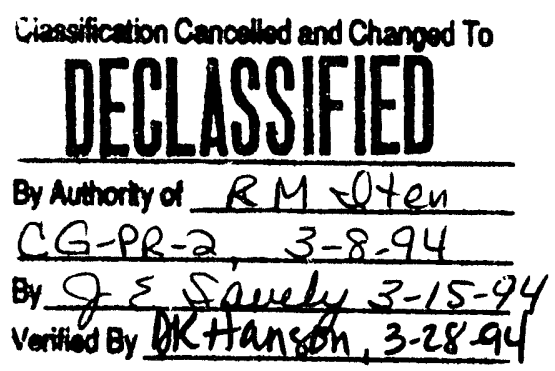

and

J. L. Jaech.

Operations Research and Synthesis

Hanford Laboratories

May, 1962

\section{HANFORD ATOMIC PRODUCTS OPERATION \\ RICHLAND, WASHINGTON}

Work performed under Contract No. AT( 45-1)-1350 between the Atomic Energy Commission and General Electric Company

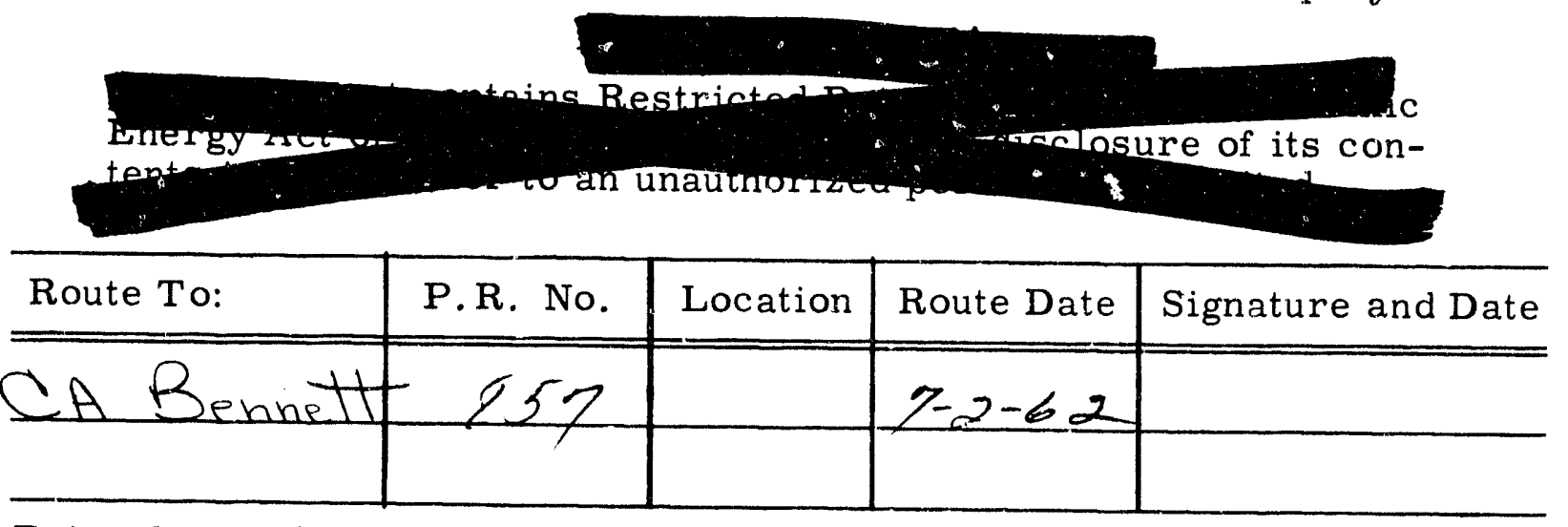

Printed in USA. Charge $\$ 1.05$. A vailable from the U.S. Atomic Energy Commission, Division of Technical Information Extension, P.O. Box 1001, Oak Ridge, Tennessee. Flease direct to the same address inquiries covering the procurement of other classified AEC reports.

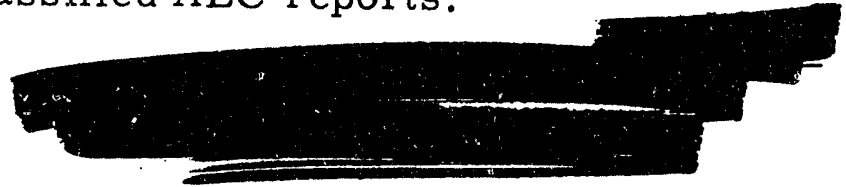




\title{
DECLLSSIFIED
}

\begin{abstract}
A study of irradiation effects on normal Hanford AlSi-canned I\&E fuels was started in March, 1959 under the name of the Quality Certification Program. This report describes the irradiation-induced effects for Warp, Tube Filling Capacity, changes in Outside Diameter, Profile Types and Break Strength, in terms of mathematical models as functions of reactor power, time, and temperature. Graphical representation of the response surfaces generated by these models are included. Future Quality Certification programs are presented.
\end{abstract}




\section{TABLE OF CONTENTS}

INTRODUCTION. $. \quad . \quad$. . . . . . . . . . . . 4

SUMMARY . . . . . . . . . . . . . . . . . 5

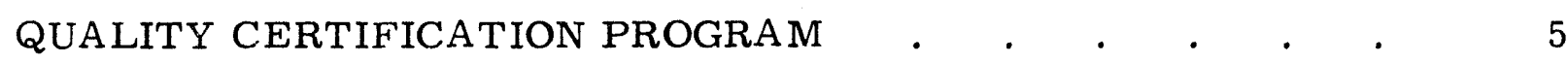

DEFINITION OF FUEL AND IRRADIATION STATISTICS . . . . 8

Fuel Element Warp . . . . . . . . . . 8

Delta Diameters . . . . . . . . . . . . 9

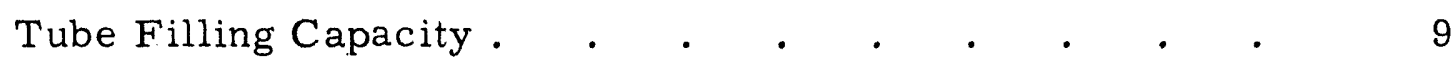

Profile Types . . . . . . . . . . . . 9

Break Strength ..$\quad$. . . . . . . . 11

APPLICATION OF DATA PROCESSING TECHNIQUES $\quad$. $\quad$ • $\quad$ - 12

MOTIVATION FOR DEVELOPING MATHEMATICAL MODELS • 16

GENERAL REMARKS ON MODEL DEVELOPMENT • • . . . 17

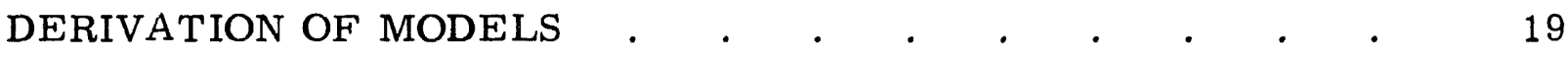

EFFECTIVENESS OF MODELS . . . • • • • . • . 25

DESCRIPTION OF RESPONSE SURFACES AND CONTOURS . • 27

COMPARISON OF PREVIOUS AND REVISED MODELS . . . . $\quad 42$

APPLICATIONS OF MODELS . • . . . . . . . . . . 48

Conclusions Based on Information Given by Models . . $\quad 48$

Uses of the Models . . . . . . . . . . 48

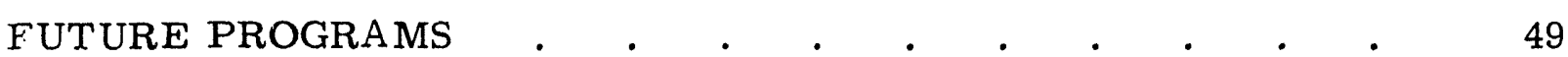

ACKNOWLEDGEMENTS . . . . . . . . . . . . . 50

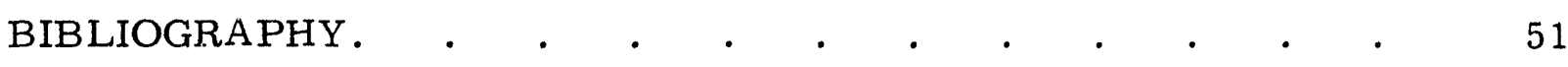




\title{
DECLLASSFIFD
}

\author{
IRRADIATION EFFECTS \\ ON NUCLEAR FUEL ELEMENTS \\ IN THE HANFORD REACTORS
}

\section{INTRODUCTION}

The Hanford reactors, graphite-moderated and light water-cooled, produce plutonium by irradiation of thick-walled tubes of aluminum-clad metallic uranium. Because of unique anisotropic properties, uranium is dimensionally unstable during irradiation. Dimensional changes in the fuel elements alter the coolant environment during irradiation, affecting both fuel and process tube life. For these reasons, much development work has been directed toward understanding and controlling uranium distortion. In evaluating fuel quality, actual irradiation performance must be used for testing because adequate out-of-reactor tests have not yet been developed. To quantitatively measure behavior of production quantities of uranium during irradiation, a continuous monitoring of normal production fuel was undertaken at Hanford in 1959. This effort, termed the "Quality Certification Program, "supplements the irradiation testing of special materials under "Production Test" conditions in support of development activities. The purpose of the Quality Certification Program was first to define and then to control important variables which affect fuel performance. (1)

This report describes the objectives of the Quality Certification Program. A major result of this program was the development of mathematical models expressing distortion as functions of reactor power, time, and temperature. The data processing techniques and the methods of statistical analyses are included to illustrate that efficient and maximum use can be made of large masses of data.

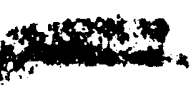




\section{SUMMARY}

1. Mathematical models were derived which express the irradiation behavior of Hanford thick-walled metallic uranium fuel elements as functions of reactor power, time, and temperature.

2. These models remove reactor effects, thus permitting the evaluation of other variables.

3. The models:

(a) show that fuel "quality" is not constant,

(b) indicate the importance of certain variables so that betier irradiation testing procedures can be developed,

(c) permit a prediction of the effects of such things as changes in fuel geometry or reactor power levels on dimensional distortion, and

(d) establish base points from which the irradiation performance of different types of fuel can be compared.

4. To accomplish the above, specialized methods of analysis and data processing techniques were developed.

\section{QUALITY CERTIFICATION PROGRAM}

Fundamental to the Quality Certification Program is the belief that much of the warp and dimensional instability in uranium fuel elements is nonrandom, and therefore can be attributed to assignable causes. Once these causes are identified and measured, they can be better controlled. The Quality Certification Program was designed to define in quantitative terms these important variables.

Uranium is a relatively new material. Until the late 1930 's, it was little more than a laboratory curiosity. Quantifying the irradiation behavior of materials in general is more of an art than a science. This is true also for uranium. Since the fuel for the Hanford reactors is metallic uranium, the variables which contribute to poor irradiation performance must be understood and characterized. 
Dimensional clearances between the fuel elements and the coolant channel walls aresmall. Thus, changes in dimensions or distortion of the fuel are potentially serious. This not only affects fuel element performance, but also limits the life of the process tubes in which the fuel is irradiated.

Fuel elements which bow or warp excessively become difficult to remove from the reactors. In addition, warped fuel elements reduce the necessary annuli clearances and upset the balanced flow conditions. Since the reactor is operated at high thermal output, even slight amounts of fuel element warp cannot be tolerated.

Dimensional instability, or changes in the dimensions of fuels as a result of irradiation, is a second serious problem. Dimensional instability may be divided into two categories known as "swelling" and "growth". The first phenomenon is caused by mutation of uranium atoms as a result of irradiation. In this process, a volume change and an accompanying decrease in apparent density occur at higher levels of exposure. Evidence indicates that swelling in uranium is primarily related to the number of fissions, rather than to the material itself. At low exposure levels, swelling is not a problem in the Hanford reactors.

Growth differs from swelling in that fuel element dimensions are altered, but no volumetric changes occur. Unlike swelling, growth may be caused by properties within the uranium itself. Thus, the process may possibly be more susceptible to control. Severe diameter growth hinders satisfactory fuel performance because it alters the flow characteristics of the coolant within the process tube, and destroys the near-optimal conditions necessary for effective heat transfer. Growth can be caused by several possibly related variables, most important of which may be grain size and orientation. These in turn may be affected by the chemical composition of the uranium.

Similarly in canning, certain variables appear to influence the integrity of the clad fuel element. Of major importance are can closure 


\section{DECLLSSSFIED}

$-7-$

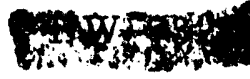

and braze integrity. The former results from welding or brazing the end caps, while the latter is produced during canning, and measured as porosity and unbondedness in the braze material between the aluminum cladding and the uranium core. These variables are important to Hanford fuel element quality, and considerable development effort has been devoted to the control of these fabrication steps.

To prevent a fuel element from restricting reactor power level increases, a testing plan to monitor the irradiation performance of routine production fuel was instituted about March, 1959. This program authorizes the routine measuring of up to 1200 irradiated normal production fuel elements per month. The major objective of this program was to establish quantitative out-of-reactor methods of predicting in-reactor fuel performance which could be used to set product specifications on fuel elements.

This Quality Certification Program measures variables of interest on the pre- and postirradiated fuel elements. This work is performed in the 300 Area Fuel Fabrication Plant preirradiation measurement facilities, and in the " $C$ " Reactor underwater Metal Examination Facility. All postirradiation measurements are made on fuel elements in the as-jacketed condition. Aluminum corrosion occurring on Hanford fuel was disregarded in these analyses. The dimensional effects on the uranium core at the higher corrosion levels, therefore, tend to be understated. The dimensional changes of jacketed fuel elements, however, are of interest from an operational viewpoint.

Over 12,000 production fuel elements have been examined and measured in the three years of the Quality Certification Program. A library of historical pre- and postirradiation data, has been established and organized for analyses with the use of electronic data processing equipment. These data have been used extensively in evaluating uranium and cladding process changes, and in analyses of irradiation performance of various materials such as dingot-ingot comparisons. They have also led to formulation of hypotheses subsequently verifiable with additional in-reactor

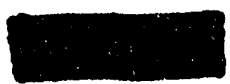


The derivation of mathematical models has been an outstanding application of these data. These models describe the irradiation behavior of Hanford elements in terms of dimensional instability and warp as functions of reactor power, time, and temperature.

\section{DEFINITION OF FUEL AND IRRADIATION STATISTICS}

For an unirradiated fuel element, dial gages are used to measure maximum and minimum outer diameters at each end of the fuel element and at the midpoint. These measurements are then used to compute average values for outer diameters at the base end, midpoint, and cap end. $\left(O D_{1}, O D_{2}\right.$, and $O D_{3}$, respectively). These three bits of data are the preirradiation input used to calculate irradiation-induced diameter changes and Tube Filling Capacity.

An irradiated fuel element is rotated until the plane of maximum bending is located, using the image projected by an optical comparator.. Five equally spaced measurements of the upper and lower profiles are then made on each image. Experience has shown each profile can be represented by a polynomial of order no higher than three. Therefore, cubic curves are fitted with orthogonal polynomials through each of the upper and lower profiles. After the optical comparator units are converted to mils using calibration factors, the resulting cubic curves are used to compute the basic statistics which describe irradiation-induced distortion.

\section{Fuel Element Warp}

The statistic "Warp" is a constant multiplied by the average of the quadratic coefficients for the upper and lower profiles and physically represents their average bending. If the fuel element exhibits a Double Bend (graphically described by the letter "s") characterized by large cubic coefficients, a slightly different method is used to define "Warp".

* Other measurements are taken, such as inner diameters, but this discussion is restricted to only those data used in this analysis. The same statement holds for the irradiated fuel element.

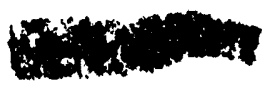




\section{Delta Diameters}

Postirradiation diameters are calculated by subtraction of one profile curve from the other and evaluation of the resulting curve at each end and at the center from these calculated values. The "net diameter changes" are found by subtracting the preirradiation measurements from these calculated values. The diameter changes at the fuel element base end, midpoint, and cap end are designated by $\Delta O D_{1}, \Delta O D_{2}$, and $\Delta O D_{3}$, respectively.

\section{Tube Filling Capacity}

Tube Filling Capacity ( $\mathrm{TFC}$ ) represents the change in maximum projected diameter of the fuel elernent, and is a measure of the combined effects of warp and diameter change. It is calculated by subtraction of the minimum point on the lower profile from the maximum point on the upper profile. The preirradiation average diameter is subtracted from this difference. rThus a TFC value of zero represents no change in projected fuel diameter.

Profile Types (Double Bend and Barrel Shape)

Another statistic used to describe the irradiation-induced distortion is a two-digit number called "Profile Type". Table I illustrates the relative proportion of fuel elements falling into the various profile categories. These data are samples of Quality Certification information and are representative of normal Hanford production fuel elements. Graphic illustrations of each Profile Type are shown along the left and top margins of Table I.

The tens position of the two--digit Profile Type describes the type of bend associated with the fuel element and is shown at the top of Table I. An empirical model has been developed for the Percent of Double Bend fuel elements for a given reactor environment. This statistic refers to the percent of fuel elements with a Type 3 profile.

The units position of the two-digit Profile Type refers to the location and amount of departure from uniform growth along the core. These profile codes are shown in the left column of Table I. The Percent of Barrel Shape 
TABLE I

DISTRIBUTION OF PROFILE TYFES

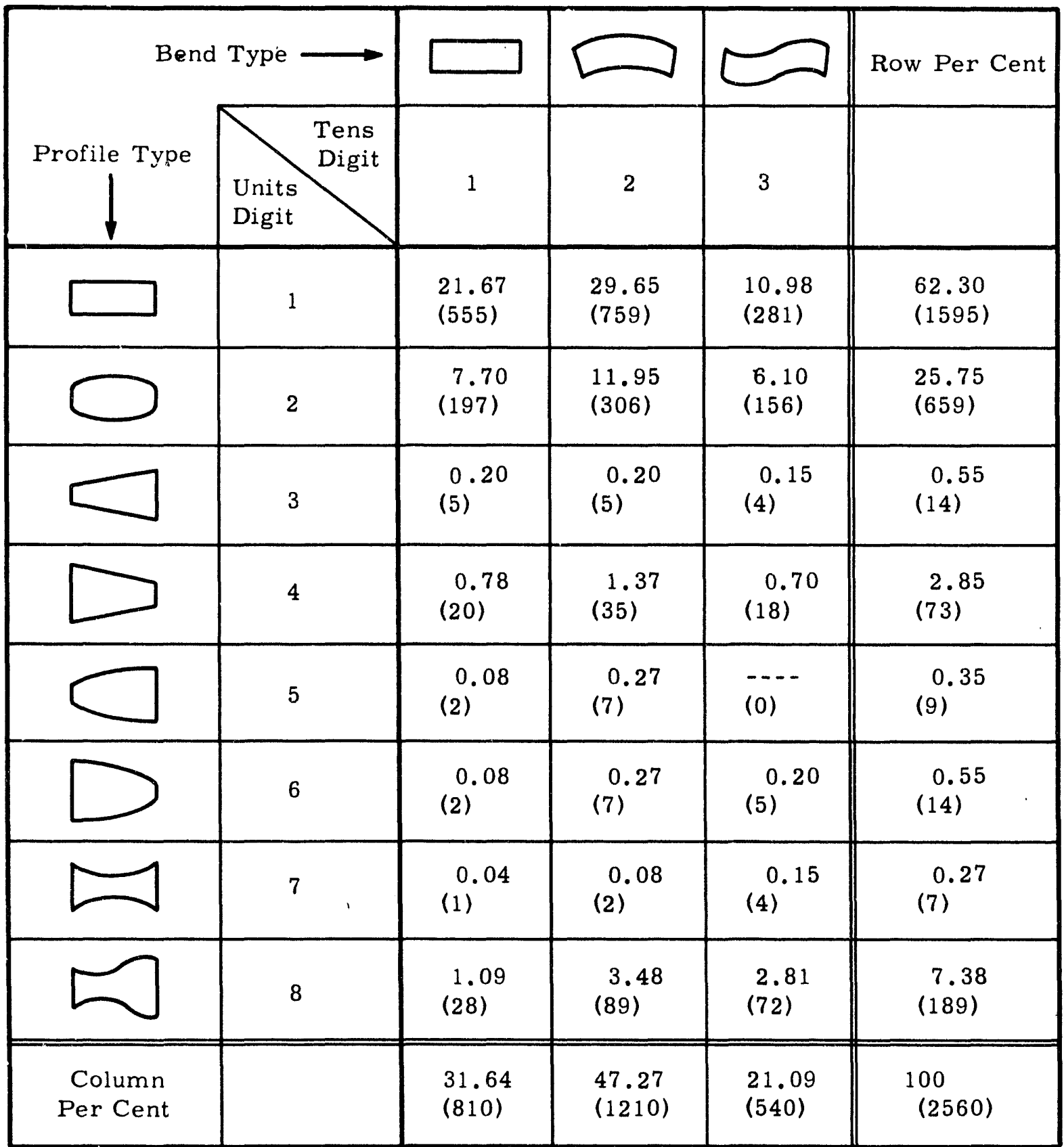

Legend: Total Number of Fuel Elements in each Cell Shown in Parenthesis. All Other Numbers are Per Cent of Total Population. 


\section{DECLLASSIFIED}

fuel elements is another statistic for which an empirical model was derived. Fuel elements with unit digit Profile Type codes of 2, 5, and 6 are included in this statistic.

Since five measurements are taken for each of the projected profiles, a fitted cubic curve may not necessarily go through all points. The extent to which it succeeds in passing through the five points is a measure of how closely the cubic curve describes the profile. Experience has shown gross discrepancies are generally due to an error in reading and/or recording one of the data points. If the d: crepancy, as measured by the sum of the squared differences between the observed points and the fitted curve, exceeds a specified critical value for one of the profiles, the fuel element is labeled a "Profile Type 80", indicative of a measurement error. With the same criterion, if both profiles show a poor fit, the fuel element is labeled a "Profile Type 90", indicative of a truly odd-shaped fuel element. Type 90 elements are rare. Both 80 and 90 Profile Types have been excluded from this study.

\section{Break Strength}

To measure the strength of uranium after irradiation, selected specimens are fractured by a load applied at the midpoint while the fuel element is supported at the ends in a horizontal position. The load required to fracture, expressed in tons of force, is called "Break Strength".

Reactor Parameters (Power, Time, and Temperature)

In addition to the computed statistics describing fuel distortion, irradiation conditions must be defined. The following parameters are based on the average reactor conditions that existed during irradiation, neglecting nonequilibrium operation.

"Power" is a calculated reactor parameter expressed as kilowatts per Hanford I\&E fuel element. It is the average calculated power generated at the fuel surface during irradiation.

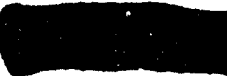


"Time" is the total integrated exposure expressed in megawatt days divided by the average daily power generation expressed in megawatts.

"Temperature" is the calculated average temperature in degrees centigrade of the external surface of the fuel in contact with the water, neglecting film.

Detailed accounts of the methods used to describe irradiation-induced distortion are documented. ${ }^{(2,3)}$ Other documents ${ }^{(4,5)}$ contain a complete description of methods used to calculate the reactor parameters, and details of the data processing system.

\section{APPLICATION OF DATA PROCESSING TECHNIQUES}

The size and scope of the Quality Certification Program make necessary the use of data processing equipment to process and analyze the resulting data. With such equipment, the "net changes" resulting from irradiation are quickly computed. The machine system within which the data have been prepared for statistical analysis has been in operation for about two years. During that time, refinements to improve the methods of computing certain reactor conditions and individual fuel statistics have been incorporated with little difficulty. The machine program has proven to be extremely flexible and capable of handling all irradiated fuel data.

The basic output generated by the computer is called the Tube Summary Report. This monthly report lists the calculated statistics for each fuel element measured during the reporting period. These data are ordered and identified by process tube within a specified reactor for each production test. (PT number 216 refers to the Quality Certification Program.)

Figure 1 is a page from a Tube Summary Report. Note the production test, reactor, and tube identification at the top. Also shown at the top of the . page are tube statistics: average tube power, residence time, average outlet water temperature, average coolant flow, canning date of the material, charge and discharge date. These data are coded to permit issuance of the report as unclassified. 


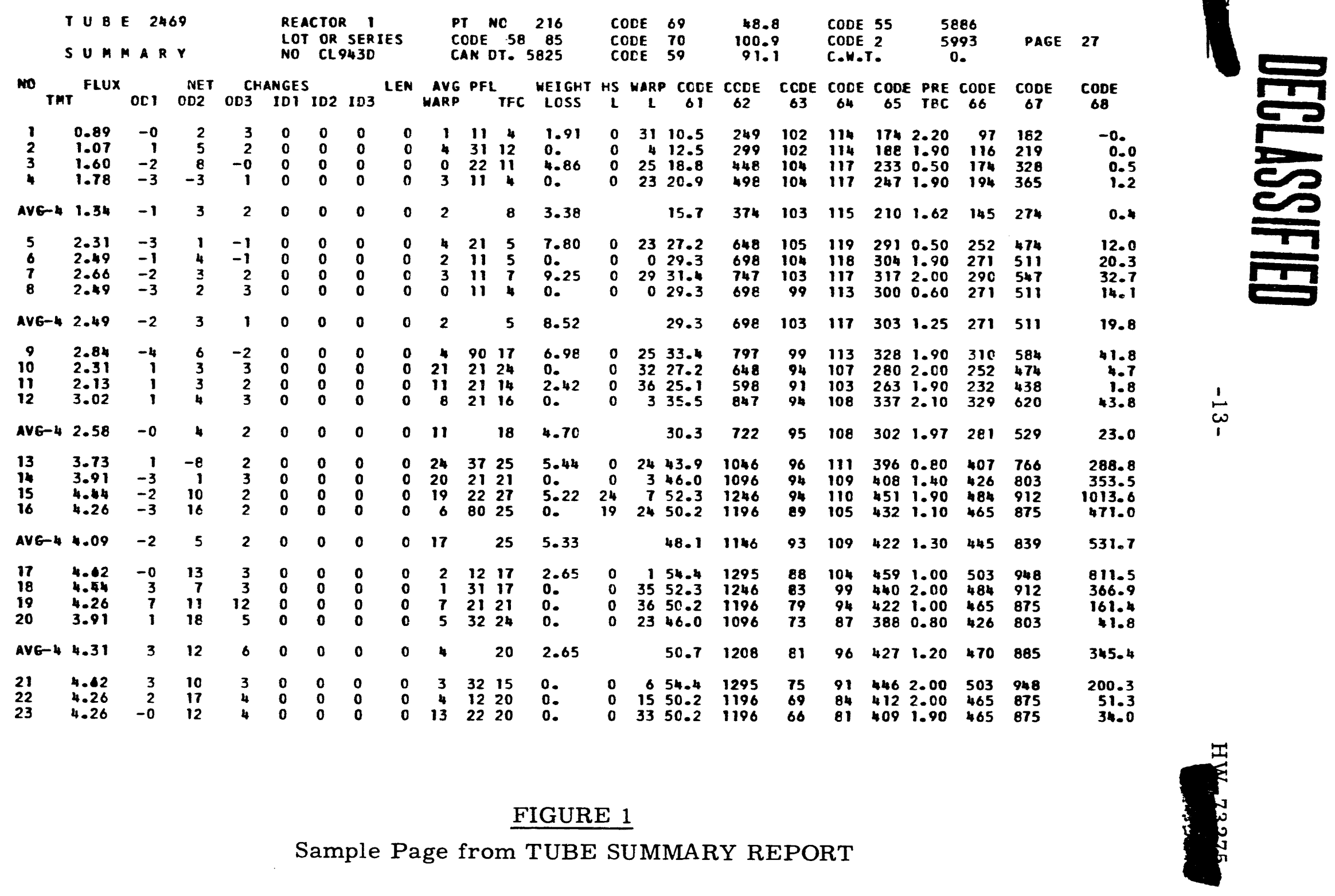


The first column refers to the position within the tube, with piece number 1 downstream. The "treatment" column is used for identification when a production test involves charging several classes of fuel in the same tube. "Flux," in column 3, comes from measurements of the gamma intensity of the irradiated piece and is used to allocate tube power to the individual fuel elements. The next three columns are $\Delta O D_{1}, \Delta O D_{2}$, and $\Delta O D_{3}$. Space is reserved in the next four columns for Inner Diameter and Length measurements, not routinely taken. Warp, Profile Type, and Tube Filling Capacity are then listed followed by Weight Loss for those fuel elements which are weighed.* The next two columns give the orientation (coded) of a "hot spot" (accelerated localized corrosion), if the fuel element has one, and of the plane of maximum warp. The final columns (again coded) are pertinent irradiation statistics which apply to the individual fuel element. In the model development, code 61 (power at the fuel element surface), tube parameter code 58 (residence time in days), and code 63 (surface temperature) were used.

From the Tube Summary data, other reports are generated for analytical purposes. One example is the Frequency Distribution Report used to investigate the relationship between two variables. The program can select data simultaneously from several sources, so in effect the relationships between sets of variables may be studied.

An example of a Frequency Distribution Report is shown in Figure 2. These data were used in the development of the mathematical models. This report represents a distribution of $\Delta \mathrm{OD}_{2}$ versus Fuel Element Power (code 61). As shown at the bottom of Figure 2, these data are restricted to production test 216 (code 45), fuel element temperatures between 76 and $95 \mathrm{C}$ (code 63), and residence times between 66 and 82 days (code 58). In the body of the report, the upper number is the number of fuel elements falling into the particular cell; the lower number is the percent of the total.

* A zero means no data were taken. If this is preceded by a minus sign, it represents a real number zero. For example, see $\Delta \mathrm{OD}_{1}$ for fuel element 1.

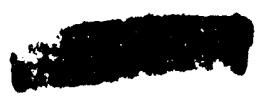




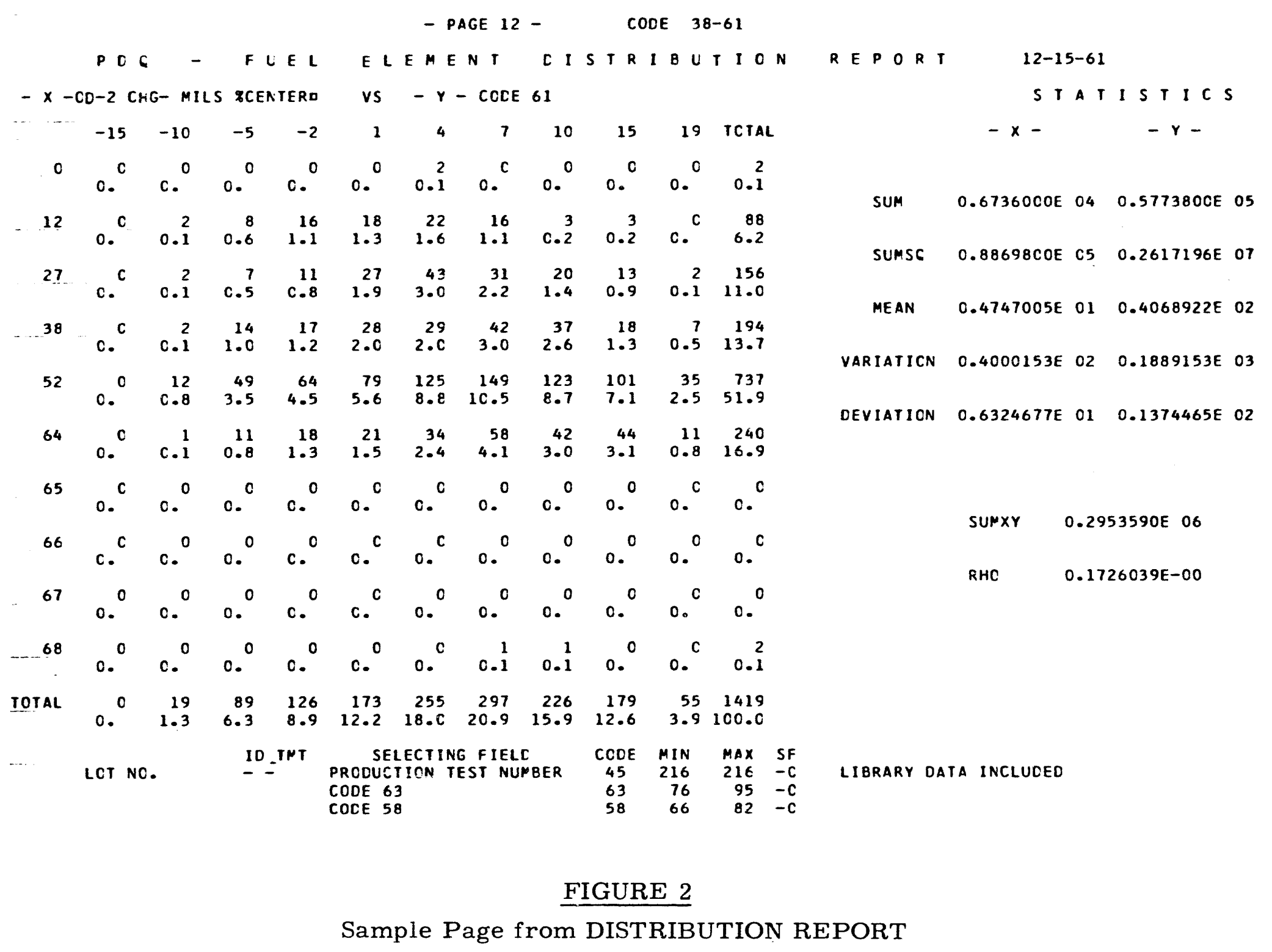


This is only one of the many reports generated from the basic data in the Tube Summary Report. It illustrates how the analyses of data can be greatly simplified through the use of data processing techniques. MOTIVATION FOR DEVELOPING MATHEMATICAL MODELS

The purpose of the Quality Certification Program is to permit a better understanding of what constitutes "Fuel Quality" and hence to improve irradiation performance. This is equivalent to finding ways to predict reactor performance on the basis of preirradiation measurements. It was recognized that in the process of finding such predictors of in-reactor performance, the information would point the way toward fuel quality improvement. For example, if a given variable were known to adversely affect fuel performance, elements exhibiting such traits could be "inspected out". However, a better method is to minimize the production of such defects by changing the process. In this way, irradiation performance would improve with no increase in reject rate.

This purpose of the Quality Certification Program should be kept in mind. If empirical models relating dimensional distortion to reactor variables do not contribute to a realization of this purpose, they must be regarded as only of academic interest. Such, however, is by no means true. Information gained through knowledgeable use of the derived models directly contributes to realization of this Quality Certification Program goal of improved irradiation performance.

That considerable variation exists in irradiation-induced dimensional distortion has long been recognized. This has been a source of difficulty in the design of irradiation testing programs. These programs compare differences between groups of fuels and develop fundamental irradiation information required for fuel technology advancement. To insure that reactor variables are comparable for both the "test" and "control" fuel elements, restricted "blocking" must be used. This is 


\section{DECLLSSFFED}

necessitated by severe environment changes occurring within a few pieces in a given process tube. This restriction has limited the scope of well designed tests in the past.

Clearly, the need existed to find some way to eliminate as much of the reactor-induced variability as possible. This was impossible before the start of the Quality Certification Program because data from "normal" production fuel elements were inadequate. Most of these data came from a few "controls" used in the Production Testing Program. Since these controls were limited in number and did not cover the complete spectrum of reactor operating conditions, data from them could not be used outside the specific test of which they were a part. An early attempt to write models for fuel performance in 1956 was only partially successful because the effort was too small to provide meaningful conclusions.

With large amounts of data generated by the Quality Certification Program, it was possible in the Fall of 1960 to derive the first set of models. The resulting models were documented, ${ }^{(4)}$ and revised early in 1961. The models discussed in this report represent the third set and include dimensional data from over 12,000 fuel elements irradiated at Hanford. These data include those used in developing previous models. GENERAL REMARKS ON MODEL DEVELOPMENT

Theoretically, one should be able to derive mathematical models relating dimensional distortion to reactor environment if one understood the mechanisms contributing to the distortion. However, the underlying mechanisms are not understood. Even if they were, it is doubtful they would be sufficiently simple to permit writing a theoretically correct model. For this reason, the empirical approach was used in developing the models.

Although lacking a theoretical basis, empirically derived models can be satisfactory from a practical standpoint, if they are accurate predictors. The primary deficiencies in empirical models are the danger 
of extrapolating beyond the range of the data for which the models were derived, and the lack of information they convey as to why fuel elements behave as they do. With these deficiencies in mind, empirically derived models have served a useful purpose in the definition of fuel behavior at Hanford.

In general terms, let $x_{1}, x_{2}, \ldots x_{k}$ represent values associated with the $\mathrm{k}$ independent reactor variables under study. Corresponding to any particular set of $x$ values there is a "response" of some sort, for example, Warp. Designate this true response by $\eta$. Due to the presence of random variation, $\eta$ is not observed directly but rather the variable $y$, which equals $\eta$ plus a random error component. There is a relationship between $\eta$ and the $x^{\prime} s$ of the form

$$
\eta=\varphi\left(x_{1}, x_{2}, \ldots x_{k}\right)
$$

or, calling the random error component $\epsilon$,

$$
y=\varphi\left(x_{1}, x_{2}, \ldots x_{k}\right)+\varepsilon
$$

In deriving the models, the function, $\varphi$, is estimated. If the theoretical form of $\varphi$ were known, the problem would consist of using the observed data to estimate the parameters of the model. In the situation under study, the form of $\varphi$ is unknown and must be estimated.

Although there are any number of expressions which can be used to fit the data, a polynomial expression for $\varphi$ is the simplest and gives adequate results. More complex surfaces require additional terms in the polynomial expression. This approach is used routinely in statistical analyses of data.

For three independent variables in the system, $(k=3)$ the simplest model would be of the form

$$
\mathrm{y}=\alpha_{0}+\alpha_{1} \mathrm{x}_{1}+\alpha_{2} \mathrm{x}_{2}+\alpha_{3} \mathrm{x}_{3}+\varepsilon
$$




\section{DECLLSSFFED}

This is called a linear model. Inclusion of quadratic terms results in the model:

$$
\begin{aligned}
\mathrm{y}= & \alpha_{0}+\alpha_{1} \mathrm{x}_{1}+\alpha_{2} \mathrm{x}_{2}+\alpha_{3} \mathrm{x}_{3}+\alpha_{11} \mathrm{x}_{1}{ }^{2}+\alpha_{22} \mathrm{x}_{2}{ }^{2}+\alpha_{33} \mathrm{x}_{3}{ }^{2} \\
& +\alpha_{12} \mathrm{x}_{1} \mathrm{x}_{2}+\alpha_{13} \mathrm{x}_{1} \mathrm{x}_{3}+\alpha_{23} \mathrm{x}_{2} \mathrm{x}_{3}+\varepsilon
\end{aligned}
$$

The addition of more terms can proceed until an adequate fit is achieved.

\section{DERIVATION OF MODELS}

Data from over 12,000 measured fuel elements were included in the development of the mathematical models. The need for this large amount of data is graphically illustrated in Figure 3. Let "fuel quality" be an undefined characteristic which varies with time. For example, this may be Warp. The three trends indicated in Figure 3 are minor variation, cyclic variation, and long term trending. A relative time scale shows the approximate duration of each.

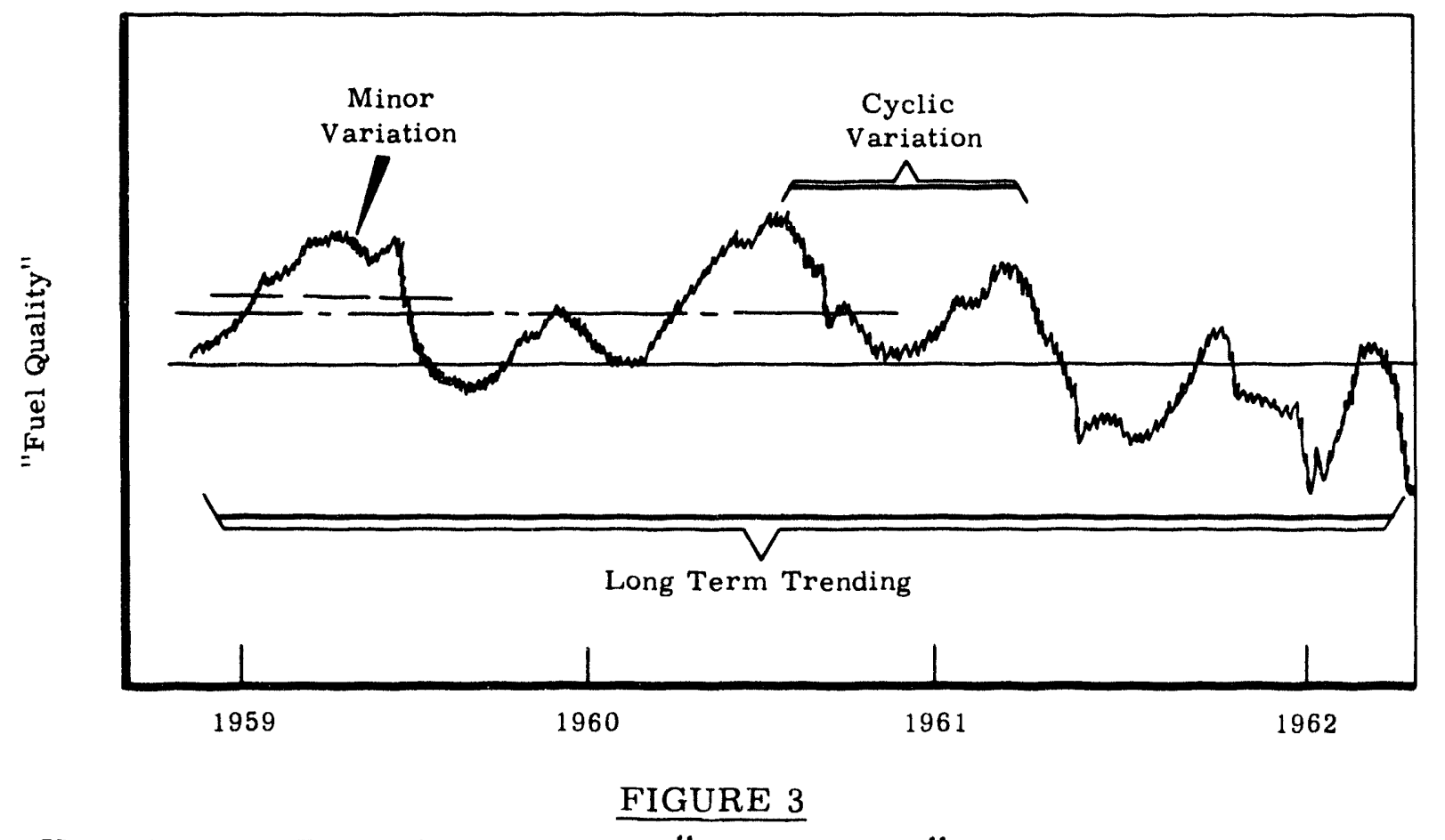

Hypothetical Example of Hanford "Fuel Quality" as a Function of Time

\section{A.}




\section{DECLLSSIFIED}

$-20-$

$\mathrm{H}$

This example illustrates in a qualitative manner the quality trends observed in Hanford fuel since the start of the Quality Certification Program. Actual fuel performance, as measured by several criteria, has improved appreciably during the past years. This improvement is due to many process changes instituted both at Hanford and the uranium production centers. Some of these changes have been initiated as a result of the Quality Certification Program.

In the presence of such nonrandom variation, there is an inherent danger in using small amounts of data to derive empirical models describing the effects of reactor environment. One must be assured that fuel elements irradiated under one environment are of comparable "quality" to those irradiated under another. If this were not true, it would be imposdible to separate environmental and fuel "quality" effects.

In a carefully controlled experiment, this assurance is attained by design. Thus, adequate models could be derived with much less data. However, in the absence of "control by design", it is achieved by randomization. Since the Quality Certification Program has additional purposes, the derivation of models can be considered a valuable by-product. With "control by randomization", greater assurance of proper identification of the various effects is achieved as the sample size increases.

In addition, the presence of cycles and trends means the estimated "average" fuel quality is dependent on the period of time over which the data were taken. Over a long time period, this average may be considered more meaningful than that over a shorter period. However, since the average as such is of limited value, this point is not too important. Of greater importance is the recognition of how much "normal" fuel quality varies around the "average" once reactor effects are removed.

In previous studies of postirradiation Warp, Diameter Change, and Tube Filling Capacity, the reactor variables of importance were found to be residence time, fuel element surface temperature, and power at the 


\section{DECLASSFFED}

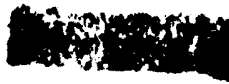

surface. Other studied variables, such as calculated core temperature, contributed little. Previous attempts have also shown that no more than a complete quadratic model is needed to adequately describe the observed responses. For this reason, a model such as (4) was initially fitted.

For simplificaticn, the independent variables were transformed as shown below, and the model given in (4) was rewritten as in (5).

Variable

$$
\begin{array}{ll}
\text { Temperature }=x_{1}\left({ }^{\circ} \mathrm{C}\right) & \mathrm{x}_{1 L}=\frac{\mathrm{x}_{1}-65}{20} \\
\text { Time }=\mathrm{x}_{2} \text { (operating days) } & \mathrm{x}_{2 L}=\frac{\mathrm{x}_{2}-90}{15} \\
\text { Power }=\mathrm{x}_{3} \text { (kw/fuel element) } & \mathrm{x}_{3 L}=\frac{\mathrm{x}_{3}-32}{12} \\
\text { Squared Terms: } & \mathrm{x}_{j Q}=\mathrm{x}_{j L}^{2}-2, j=1,2,3 \\
y=\beta_{0}+\beta_{1} \mathrm{x}_{1 L}+\beta_{2} \mathrm{x}_{2 L}+\beta_{3} \mathrm{x}_{3 L}+\beta_{11} \mathrm{x}_{1 Q}+\beta_{22} \mathrm{x}_{2 Q} \\
+\beta_{33} \mathrm{x}_{3 Q}+\beta_{12} \mathrm{x}_{1 L} \mathrm{x}_{2 L}+\beta_{13} \mathrm{x}_{1 L} \mathrm{x}_{3 L}+\beta_{23} \mathrm{x}_{2 L} \mathrm{x}_{3 L}+\varepsilon
\end{array}
$$

With respect to the dependent variables, square root transformations were made in the case of Warp and TFC. This was done to stabilize the variance. To explain further, for example, if a group of fuel elements have an average warp of 5 mils, the variability between the warps of the individual fuel elements is considerably less than on fuel elements having an average warp of 10 mils. Since comparable variation throughout the range of the data is necessary for the analysis, a square root transformation was used to achieve this. This transformation presents no difficulty in the interpretation of results when the reason is understood. The effect of the square root transformation on the variation is illustrated graphically in Figure 4. No transformations were found necessary in the case of diameter changes. 

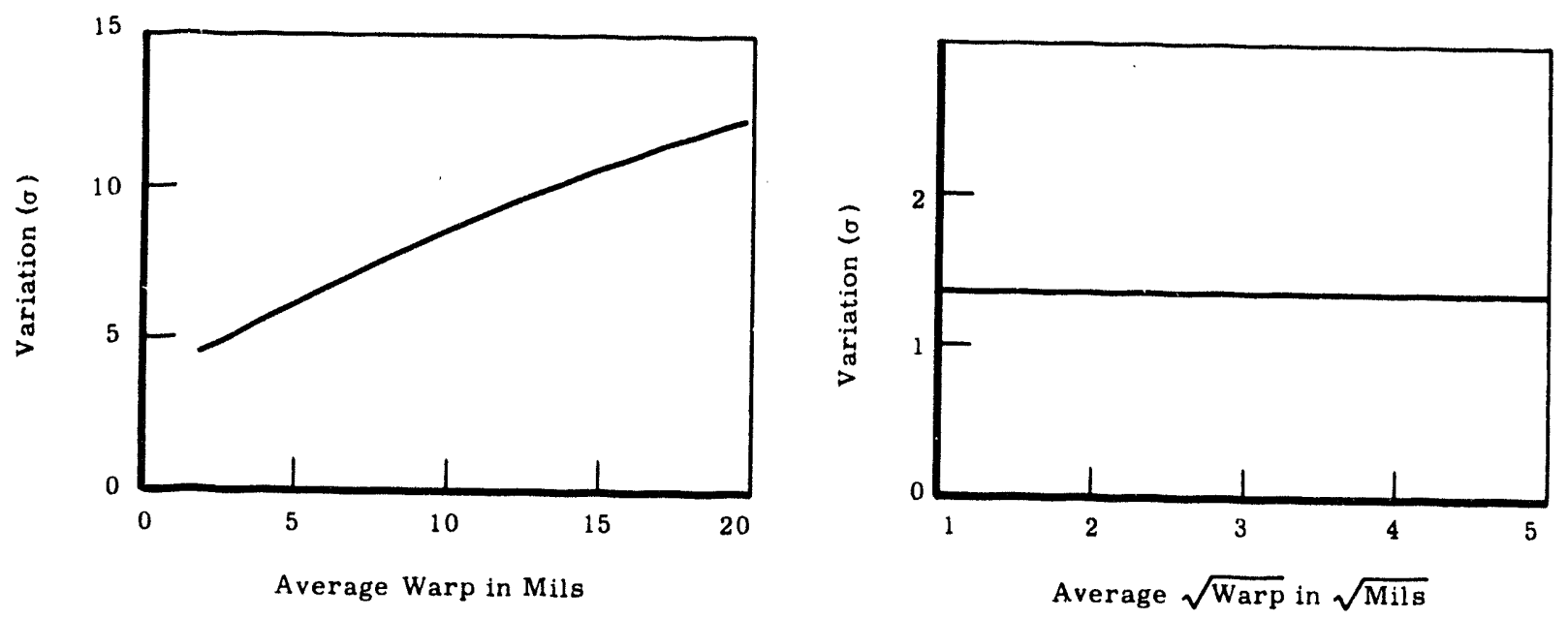

FIGURE 4

Effect of Square Root Transformation on Variation for Warp

In estimations of Beta coefficients in (5), the raw data consisted of observed Warp (or $\mathrm{TFC}, \triangle \mathrm{OD} \mathrm{D}_{1}$, etc) and the associated reactor parameter values for each of the fuel elements included in the study. With the Frequency Distribution Report prepared by the IBM 7090 and illustrated in Figure 2, the data were grouped into 92 cells of power, time, and temperature. Within each cell, the average value for the dependent variable was calculated. In the case of the dependent variables "Barrel Shape" and "Double Bend", the statistic computed was simply the percent of fuel elements within each cell having Barrel Shape or Double Bend profiles.

Standard methods of weighted regression analysis were used to estimate the Beta parameters. This was done with a generalized least squares regression analysis routine on the IBM 7090. The results of the initial fits indicated the complete quadratic model was not generally needed. Revised models. were therefore estimated. Only a few seconds of computing time were needed to fit each model. This means that several models could easily be investigated and the simplest selected. 


\section{UEELLSSSFFED}

The estimated coefficients of the selected models are given in

Table II where the notation comes from equation (5).

TABLE II

\section{COEFFICIENTS FOR EMPIRICALLY DERIVED MODELS}

\begin{tabular}{|c|c|c|c|c|c|c|c|}
\hline & $\sqrt{\text { Warp }}$ & $\sqrt{\mathrm{TFC}}$ & $\Delta O D_{1}$ & $\Delta \mathrm{OD}_{2}$ & $\Delta \mathrm{OD}_{3}$ & $\begin{array}{c}\% \text { Barrel } \\
\text { Shape } \\
\end{array}$ & $\begin{array}{c}\% \text { Double } \\
\text { Bend } \\
\end{array}$ \\
\hline$\beta_{0}$ & 2.202 & 3.511 & -0.452 & 4.382 & -1.064 & 27.027 & 26.410 \\
\hline$\beta_{1}$ & $\ldots$ & -0.011 & -- & -0.073 & $\cdots$ & -0.027 & 0.510 \\
\hline$\beta_{2}$ & 0.139 & 0.149 & -0.033 & 0.414 & $\cdots$ & 3.001 & 2. 253 \\
\hline$\beta_{3}$ & 0.206 & 0.300 & 0.201 & 1.222 & --- & 8. 463 & 3.495 \\
\hline$\beta_{11}$ & --- & -0.070 & --- & -0.463 & $-\cdots-$ & -2.291 & -1.314 \\
\hline$\beta_{22}$ & -0.032 & -0.005 & 0.131 & 0.126 & $\cdots$ & 0.102 & -0.320 \\
\hline$\beta_{33}$ & -0.074 & -0.051 & 0.053 & 0.061 & -- & -0.678 & -2.257 \\
\hline$\beta_{12}$ & -- & -- & -- & -- & -- & $\cdots$ & -0.446 \\
\hline$\beta_{13}$ & --- & --- & -- & $\cdots$ & $\cdots$ & --- & 0.954 \\
\hline$\beta_{23}$ & -- & 0.019 & -- & 0.213 & $\cdots$ & 0.773 & 0.366 \\
\hline
\end{tabular}

Note the simple models for Warp and $\triangle O D_{1}$ in which temperature is not a significant variable and which contain no significant interactions. Although temperature was included in previous models, it was not too important a variable and could have been excluded.

It is emphasized that the specific models presented are based on a certain product "mix." This affects primarily the $\beta_{0}$ term, and does not impair the usefulness of the models.

In addition to the models represented in Table II, another was derived for Break Strength based on 558 fuel elements. This sample was smaller, since very few fuel elements are subjected to the Break Strength test. With this number of fuel elements, the specific model is influenced 
to a greater extent by the product mix. Nevertheless, there is enough consistency to permit reporting the results of this analysis. In this instance, the regression was made on the original 558 data points rather than on cell averages after grouping. The simplified model is written in (6)

$$
\begin{aligned}
\text { Break Strength (tons) }= & 12.287-0.245 \mathrm{x}_{2 \mathrm{~L}}-1.249 \mathrm{x}_{3 \mathrm{~L}} \\
& +0.121 \mathrm{x}_{3 \mathrm{Q}}+0.061 \mathrm{x}_{2 \mathrm{~L}} \mathrm{x}_{3 \mathrm{~L}}
\end{aligned}
$$

As shown in Figure 5, Break Strength decreases very rapidly immediately after charging for higher powered fuel elements. Following this initial dramatic decrease in strength, the rate of change decreases with continued irradiation.

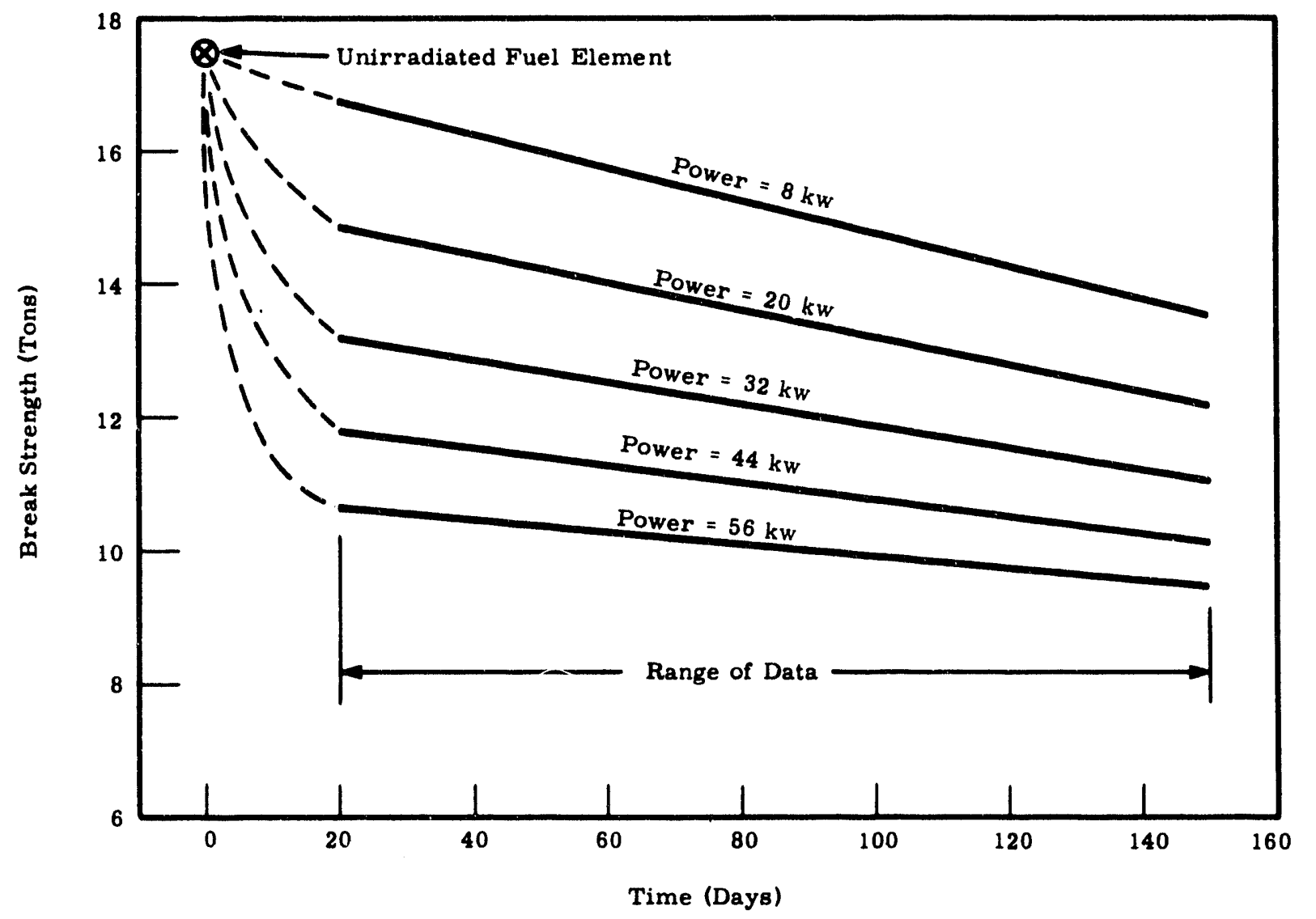

FIGURE 5

Effect of Power and Time 


\section{DECLLSSFFED}

\section{EFFECTIVENESS OF MODELS}

To be effective, a model should be as simple as possible, and give an adequate fit to the data. The degree to which a particular model describes a set of data is called the "goodness of fit."

One measure of goodness of fit is the multiple correlation coefficient $p$. This is a measure of the agreement between the observed points and those predicted by the model. A $\rho$ of 1 means all the variation is removed by the model (perfect correlation); a $\rho$ of 0 means none of the variation is removed. The percent of the variation removed by a given model is found by squaring the correlation coefficient $\rho$ and multiplying by 100. For example, in the case of Warp, with $\rho=0.83,69$ percent of the variation is removed.

It does not necessarily follow that another model must be found merely because of a low correlation coefficient. If the original variation between cell averages is not excessive, there is none to remove. "Withincell" variability is used to determine how much of the initial variation between cell averages is removable. Let

$$
\begin{aligned}
& \sigma_{0}^{2}=\text { within-cell variance, } \\
& \sigma_{1}^{2}=\text { total variance before fitting the model, and } \\
& \sigma_{2}^{2}=\text { total variance after fitting the model. }
\end{aligned}
$$

$\rho$ is defined

$$
\rho^{2}=\frac{\sigma_{1}^{2}-\sigma_{2}^{2}}{\sigma_{1}^{2}} .
$$

If $\rho_{1}^{2}$ is further defined as the "limiting" correlation coefficient

$$
\rho_{1}^{2}=\frac{\sigma_{1}^{2}-\sigma_{0}^{2}}{\sigma_{1}^{2}},
$$


then, for a "perfect" fit, $\delta$, defined below, should be zero.

$$
\begin{aligned}
\delta & =\rho_{1}^{2}-\rho^{2} \\
& =\frac{\sigma_{2}^{2}-\sigma_{0}^{2}}{\sigma_{1}^{2}} .
\end{aligned}
$$

In Table III, values of $\rho$ and $\delta$ are given for each of the models.

TABLE III

\section{$\rho$ and $\delta$ Values on Models}

\begin{tabular}{lcc} 
& $\rho$ & $\delta$ \\
\cline { 2 - 3 }$\sqrt{\text { Warp }}$ & 0.83 & 0.20 \\
$\sqrt{\text { TFC }}$ & 0.93 & 0.01 \\
$\Delta \mathrm{OD}_{1}$ & 0.49 & 0.49 \\
$\Delta \mathrm{OD}_{2}$ & 0.86 & 0.20 \\
$\triangle \mathrm{OD}_{3}$ & 0.00 & 0.53 \\
$\%$ Barrel Shape & 0.92 & 0.02 \\
$\%$ Double Bend & 0.88 & 0.07
\end{tabular}

With the $\delta$ criterion, the $\sqrt{\mathrm{TFC}}, \%$ Barrel Shape, and \% Double Bend models provided excellent fits. For $\sqrt{\text { Warp }}$ and $\triangle O D_{2}$, the fit is not as good. It is doubtful, however, if the lack of fit is serious enough to warrant more complicated models. For $\triangle \mathrm{OD}_{1}$ and $\triangle \mathrm{OD}_{3}$, the models are still less effective. This is not particularly disturbing since these characteristics are relatively stable compared with $\Delta \mathrm{OD}_{2}$. In fact for $\triangle O D_{1}$ and $\triangle O D_{3}$, the variances between cell averages before fitting are smaller than for $\triangle O D_{2}$ after fitting the models.

A good way to depict these results graphically is to consider the estimates of the within-cell variance $\sigma_{0}^{2}$. The uncertainty due to sampling variability of a given cell average is $\sigma_{0}^{2} / \mathrm{N}$, where $\mathrm{N}$ is the number of fuel elements comprising the average. Therefore, the extent to which the 


\section{DECLLSSFFED}

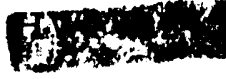

average values for each observed cell depart from those predicted should be governed by the size of the variance $\sigma_{0}^{2} / \mathrm{N}$. If the departures are "too large, " it is concluded they are not random and other terms should be included in the model. On the other hand, if the variation of the cell averages is as expected, it is concluded the fit is adequate.

"Goodness of fit" curves are plotted in Figures 6 through 12 . The limits shown are $\pm 3 \sigma_{0} / \sqrt{\mathrm{N}}$, such that for a good fit, most of the points should fall inside. It is concluded the fits are adequate.

In view of the small number of fuel elements involved in the Break Strength data, this "goodness of fit" criterion cannot be used. The fairly high correlation coefficient of 0.78 observed, however, indicates the model removes about 61 percent of the total variation.

\section{DESCRIPTION OF RESPONSE SURFACES AND CONTOURS}

The relationship between three variables may be displayed as a response surface, or by contours. A response surface has the advantage that it produces a mental image of the three dimensional solid. It has inherent disadvantages in that interpolation between reference lines is difficult and certain areas of the response surface may be obscured from view. Contour maps, on the otherhand, are more difficult to visualize in solid form, but they are easily interpretable. For these reasons, both response surfaces and contour maps are presented in Figures 13 through 19. Salient observations from these figures follow.

1. All response surfaces, except Break Strength and $\Delta \mathrm{OD}_{1}$, show minima at low values of power, time, and temperature. Maxima occur for all variables except Break Strength at high values of power, time and temperature.

2. $\triangle O D_{1}$ reaches a minimum at low power after an irradiation of about 90 days. This behavior is not explained, but other evidence suggests this observation may be real and that an actual contracof the fuel element may occur during early stages of irradiation. 

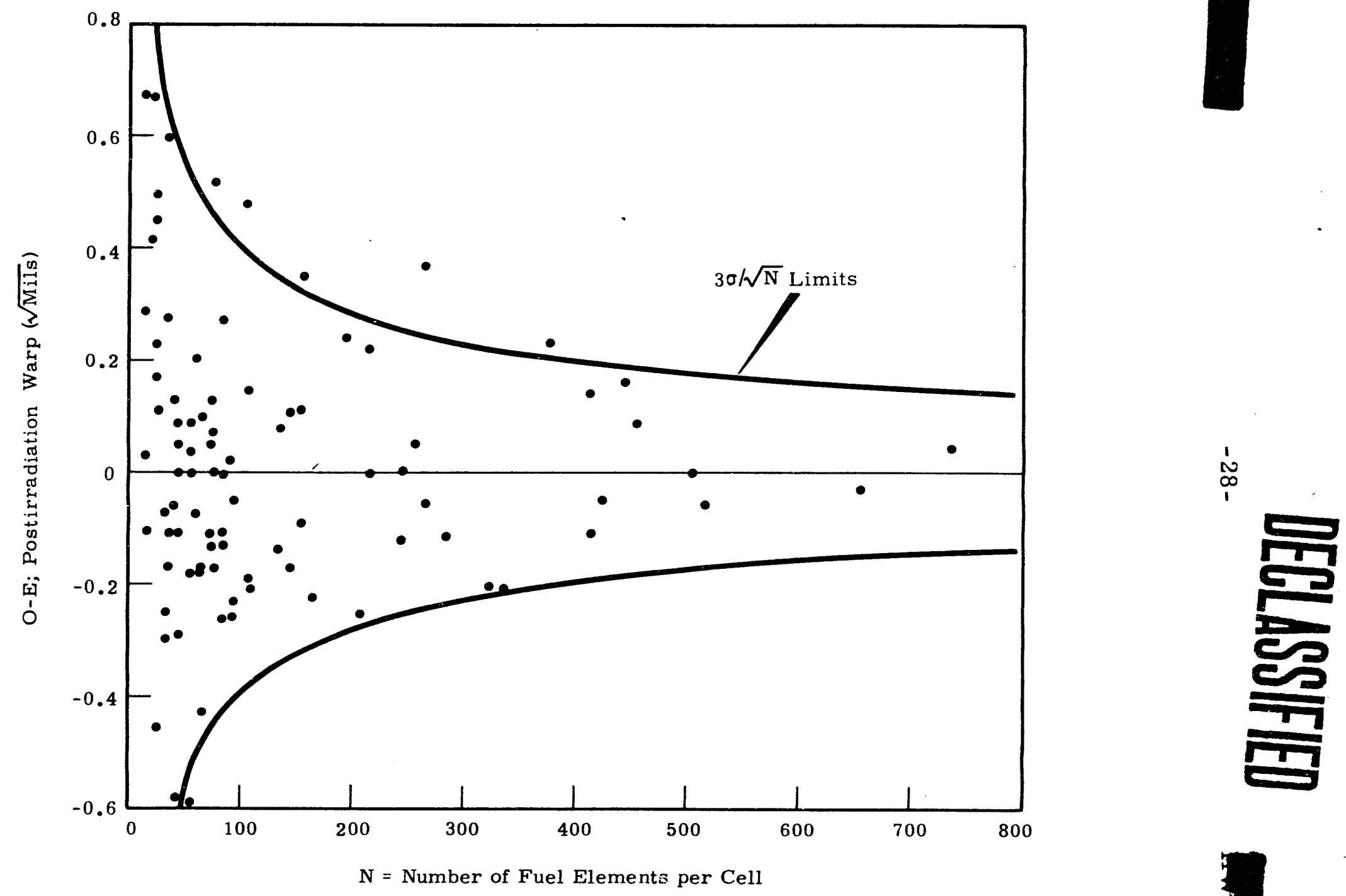

FIGURE 6

Goodness of Fit Postirradiation Warp 

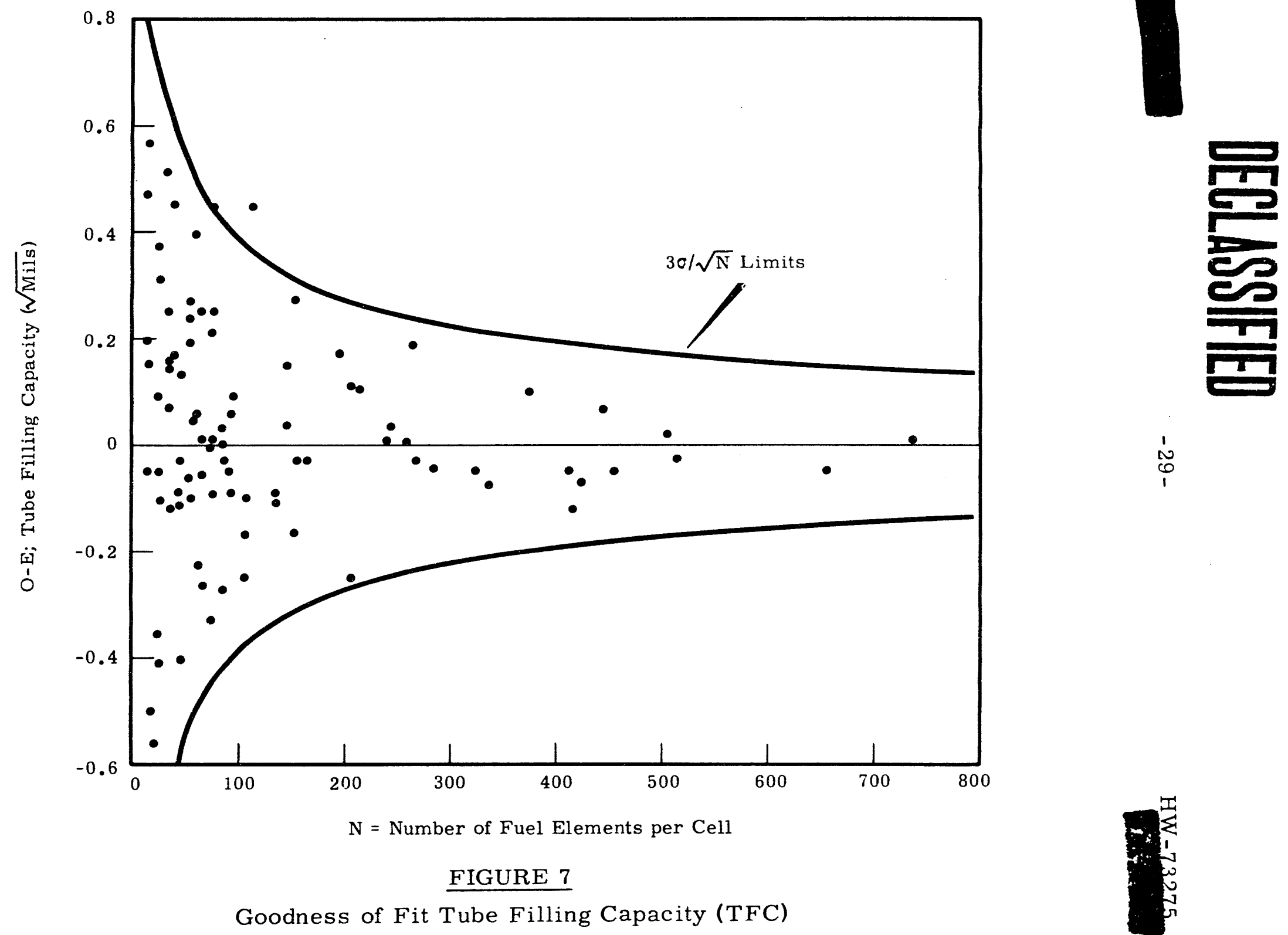


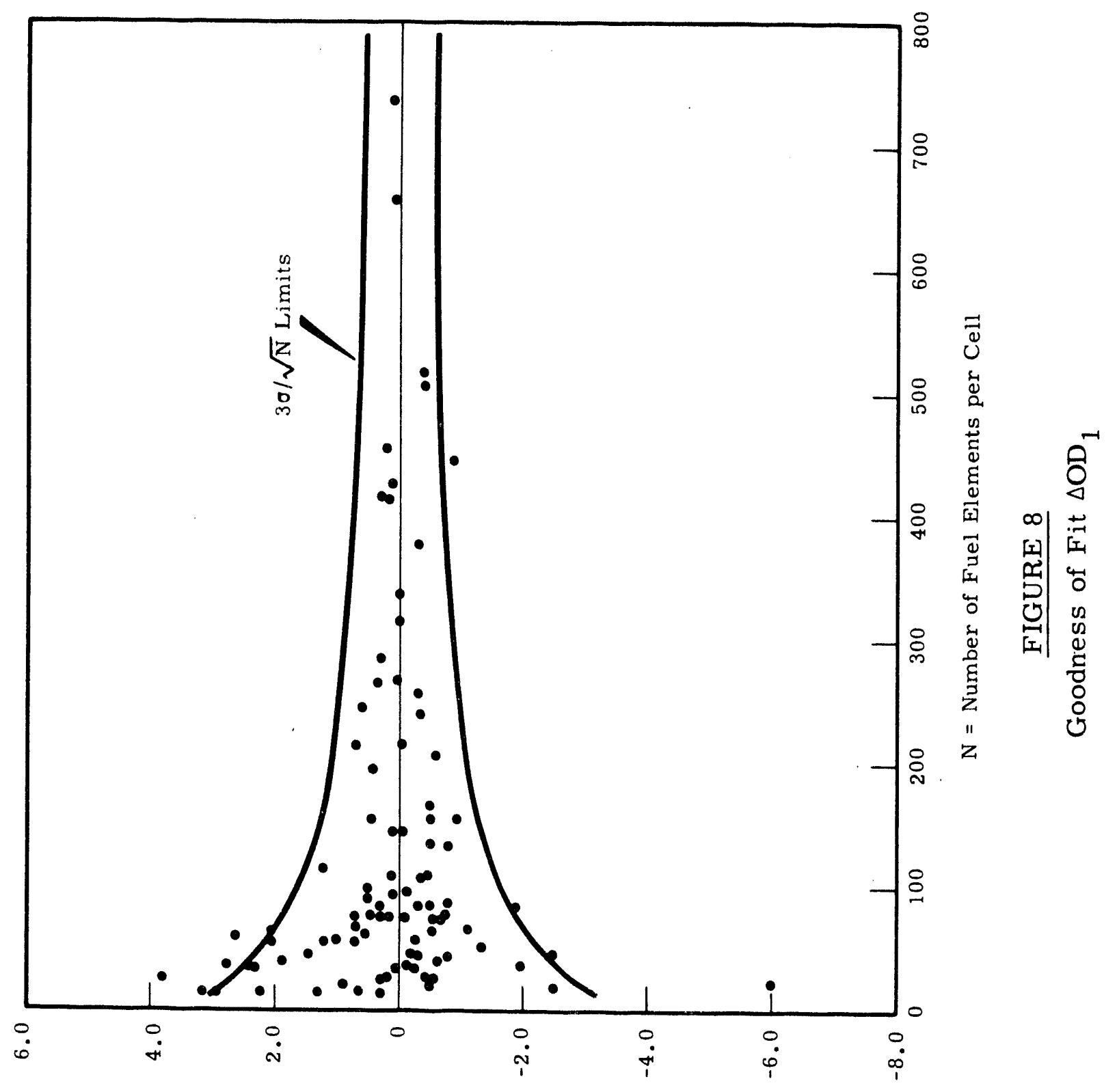

(

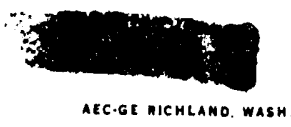



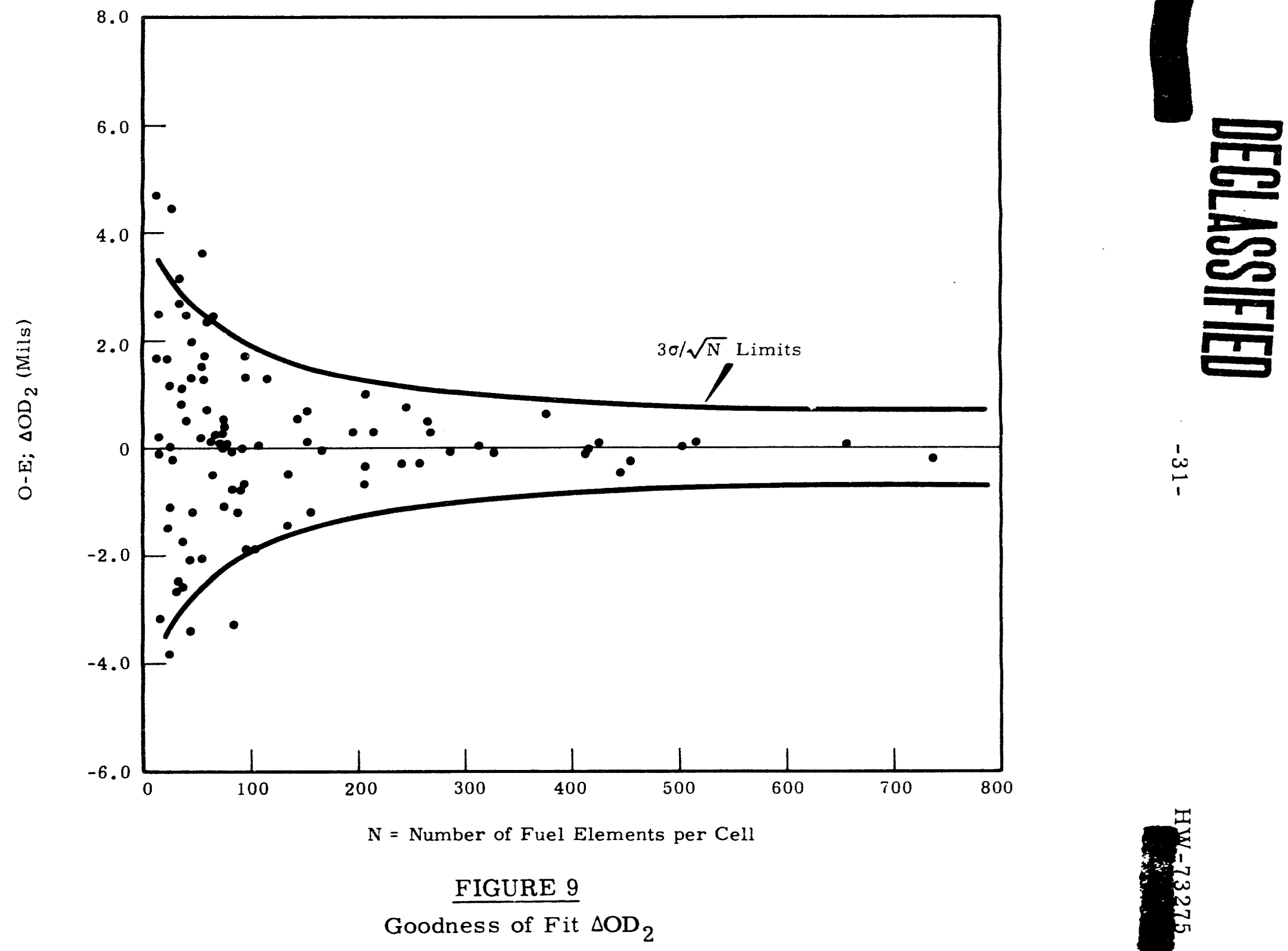

$\stackrel{1}{\omega}$

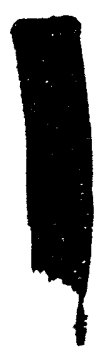

Goodness of Fit $\Delta \mathrm{OD}_{2}$ 

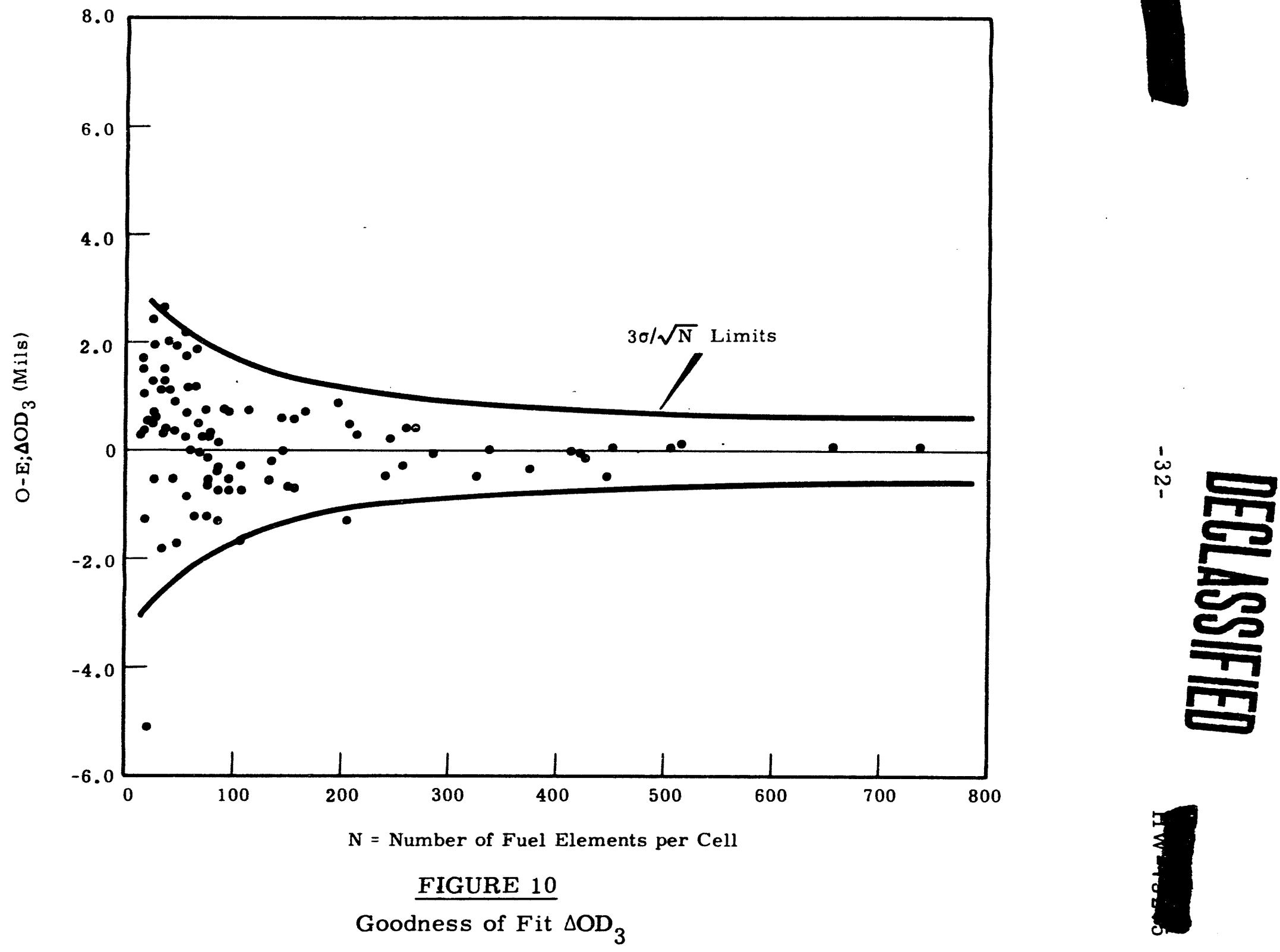

I 


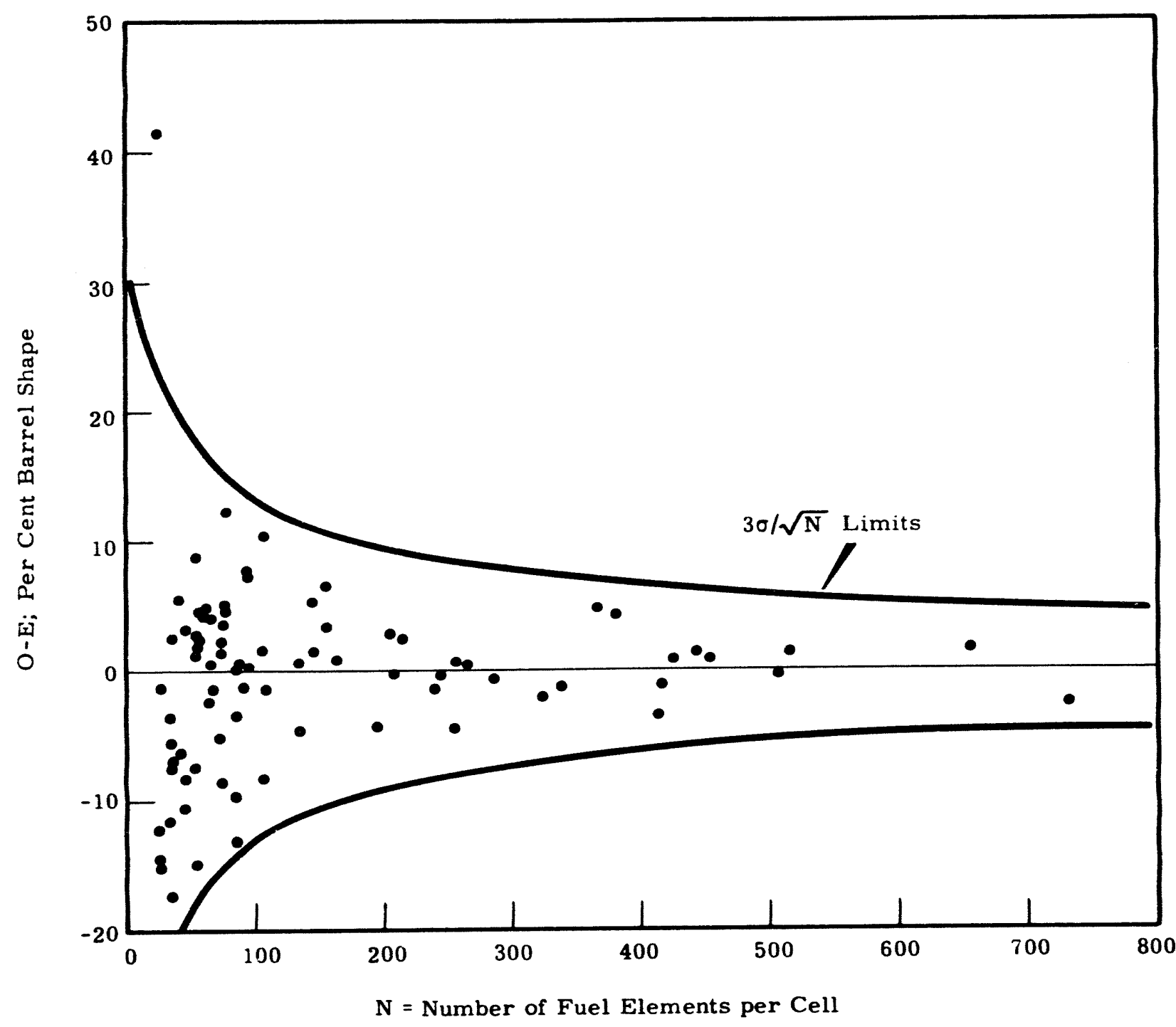

FIGURE 11

Goodness of Fit Percent Barrel Shape 

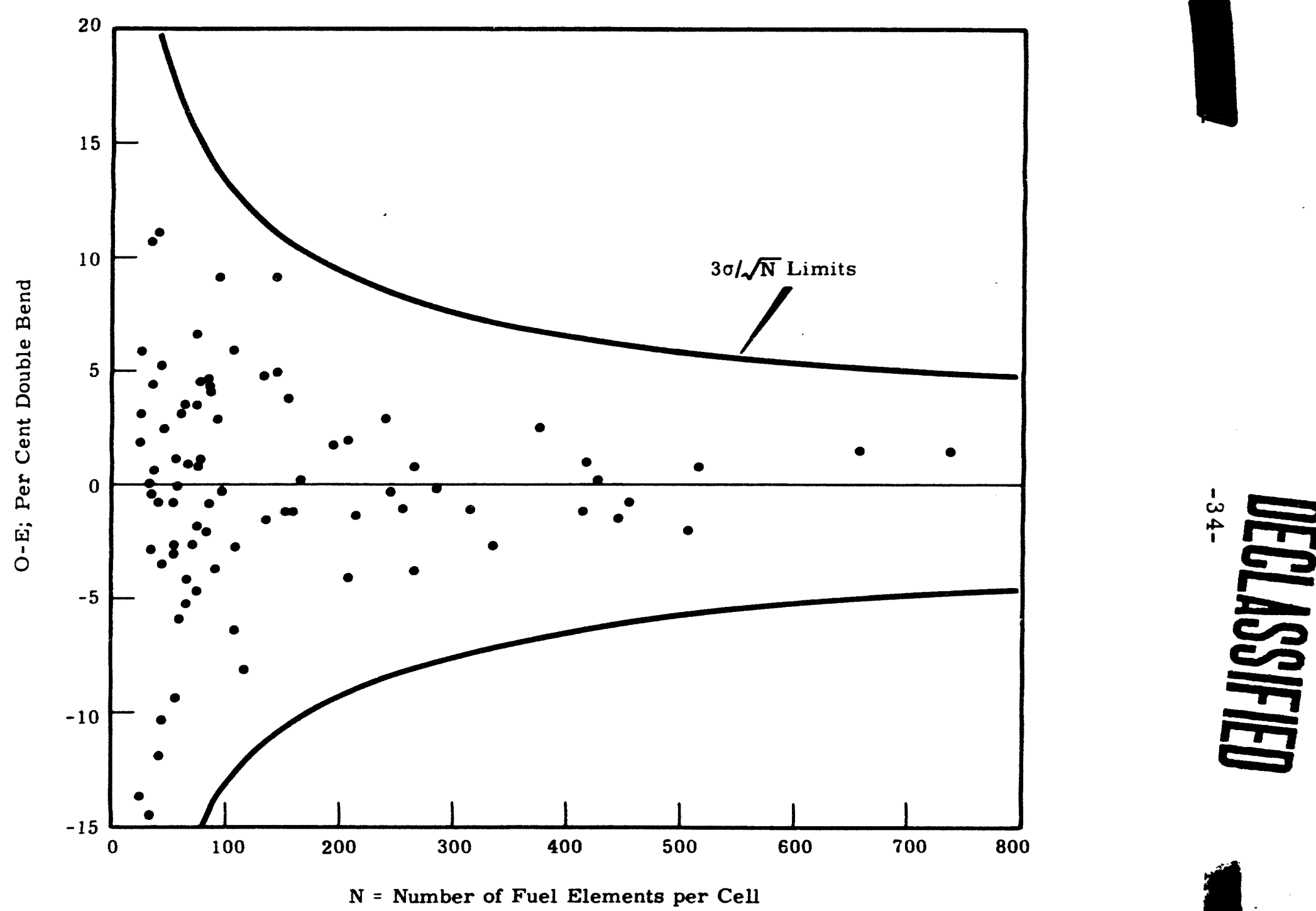

FIGURE 12

Goodness of Fit Percent Double Bend 


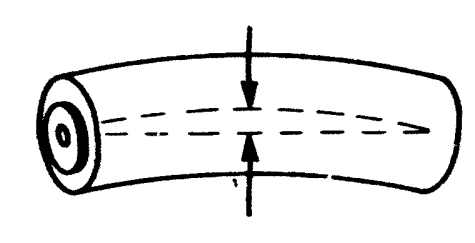

Average Warp Expressed

in $\sqrt{\mathrm{mils}}$
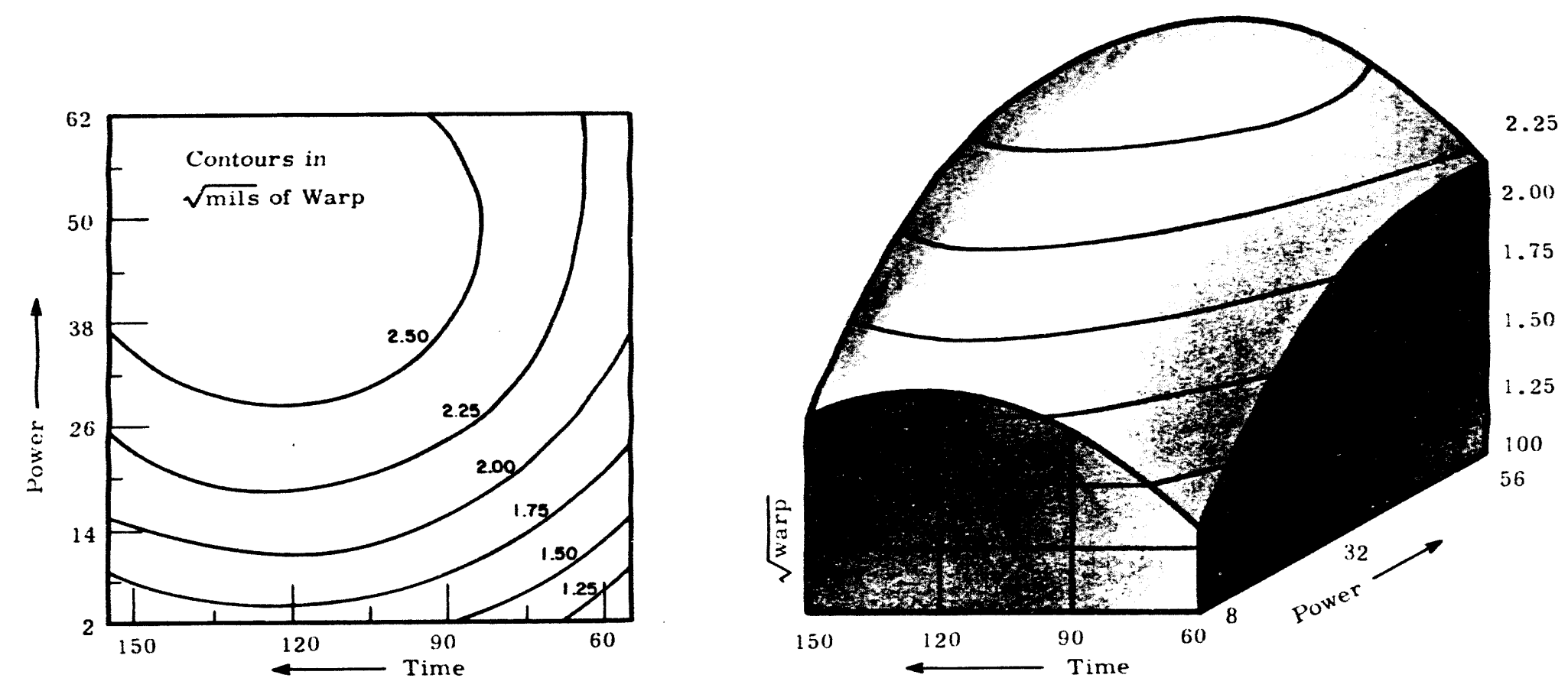

Response Surface for Warp

\section{FIGURE 13}

Effect of Power and Time on Warp of Hanford I\& E Fuel Elements 


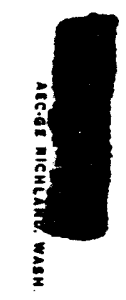

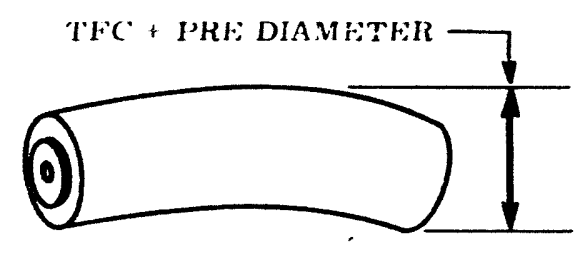

TFC Expressed In $\sqrt{\text { mils }}$

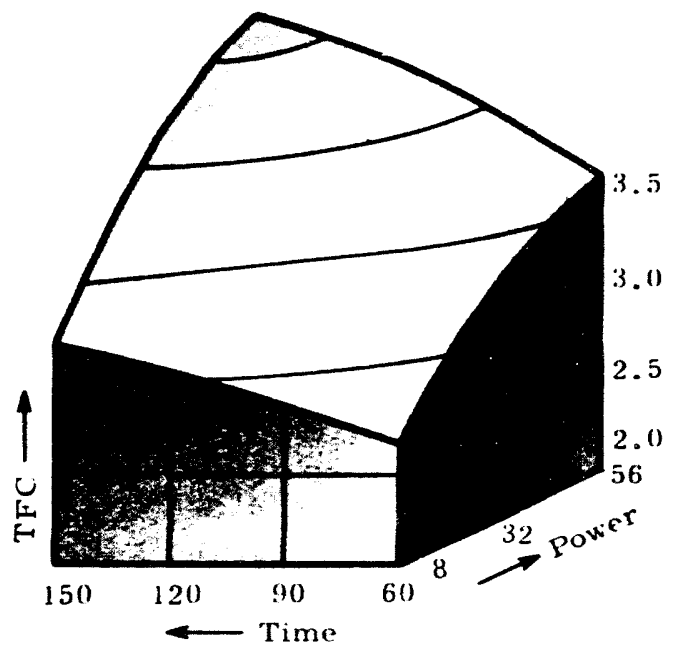

Response Surface for Tube Filing Caparity at $65^{\circ} \mathrm{C}$

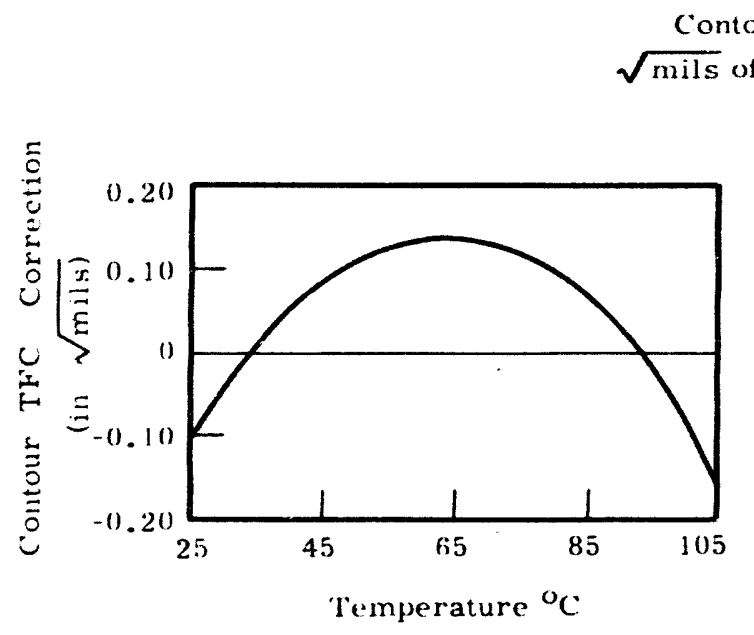

Contour in

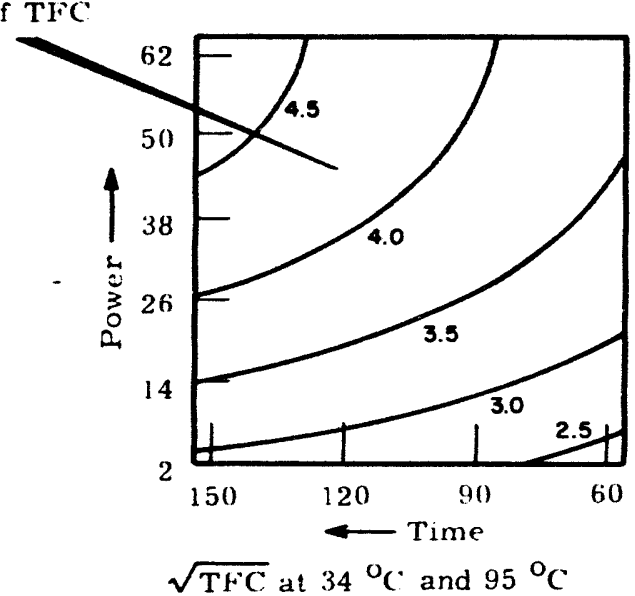

\section{FIGURE 14}

Effect of Power, Time, and Temperature on Tube Filling Capacity (TFC) on Hanford I\&E Fuel Elements

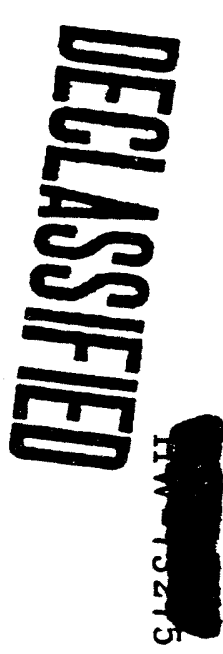



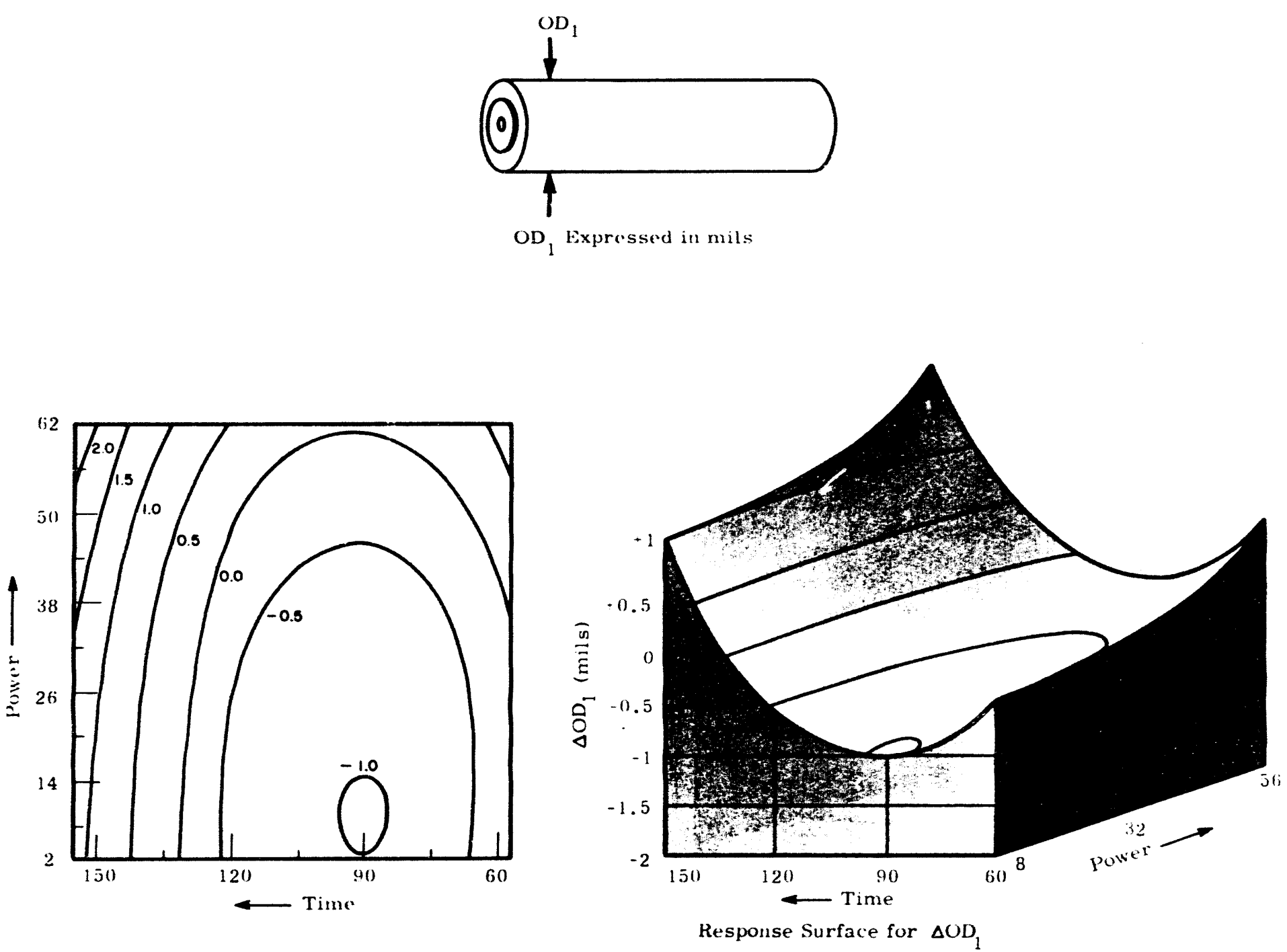

FIGURE 15

Effect of Power and Time on $\Delta O D_{1}$ (Base End) of Hanford I\&E Fuel Elements 

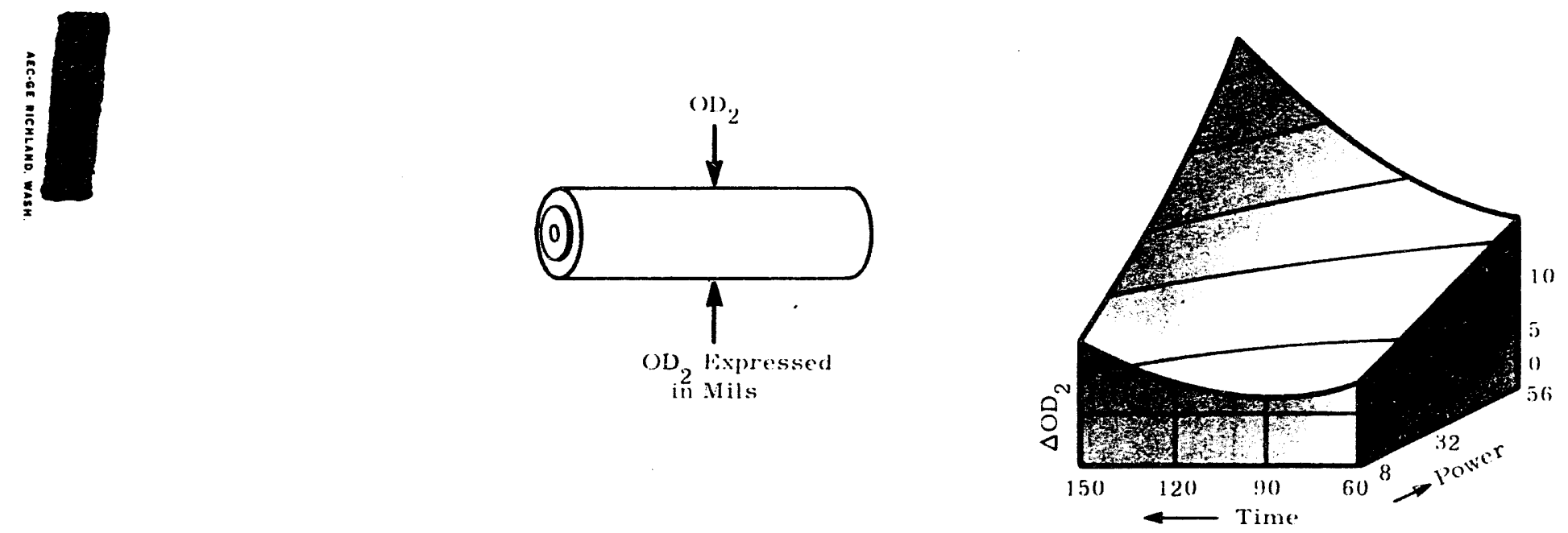

Response Surface for $\Delta O D_{2}$
at 65 o $:$
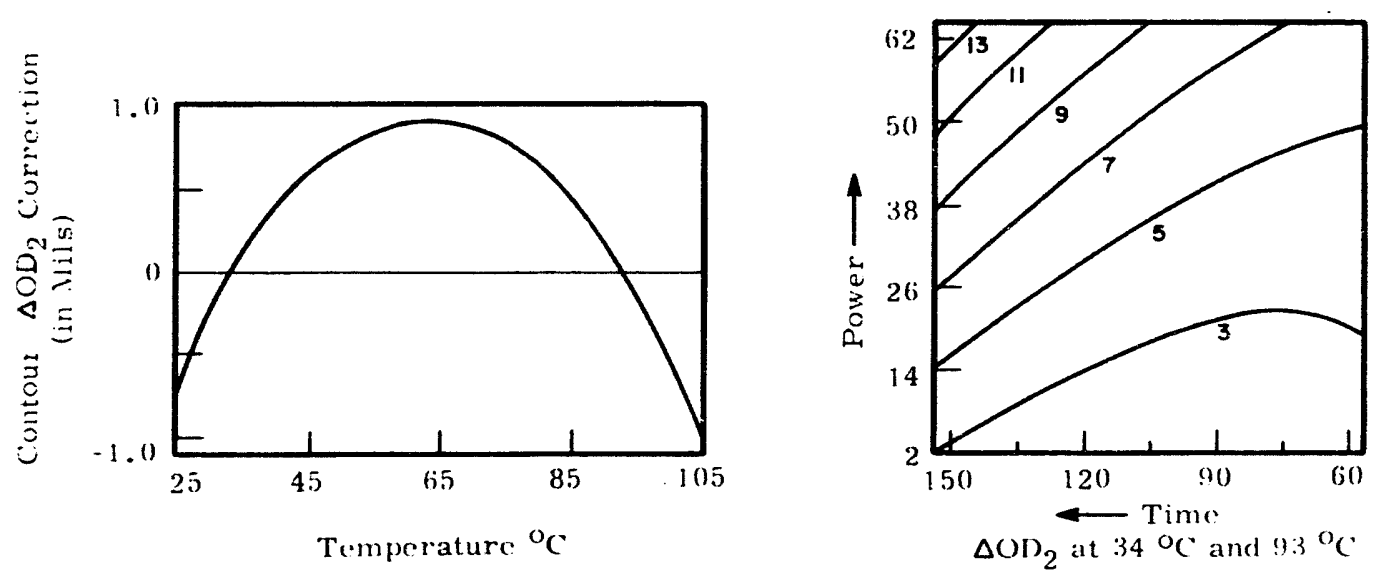

$\stackrel{1}{\omega}$

FIGURE 16

Effect of Power, Time, and Temperature on $\Delta \mathrm{OD}_{2}$ of Hanford I\&E Fuel Elements 


\section{DECLLSSSFIED}

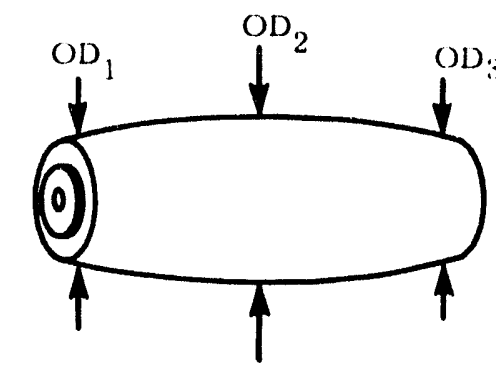

$\Delta \mathrm{OI}_{2} \geqslant 4$ mils Larger Than $\triangle O D_{1}$ or $\triangle O D_{3}$

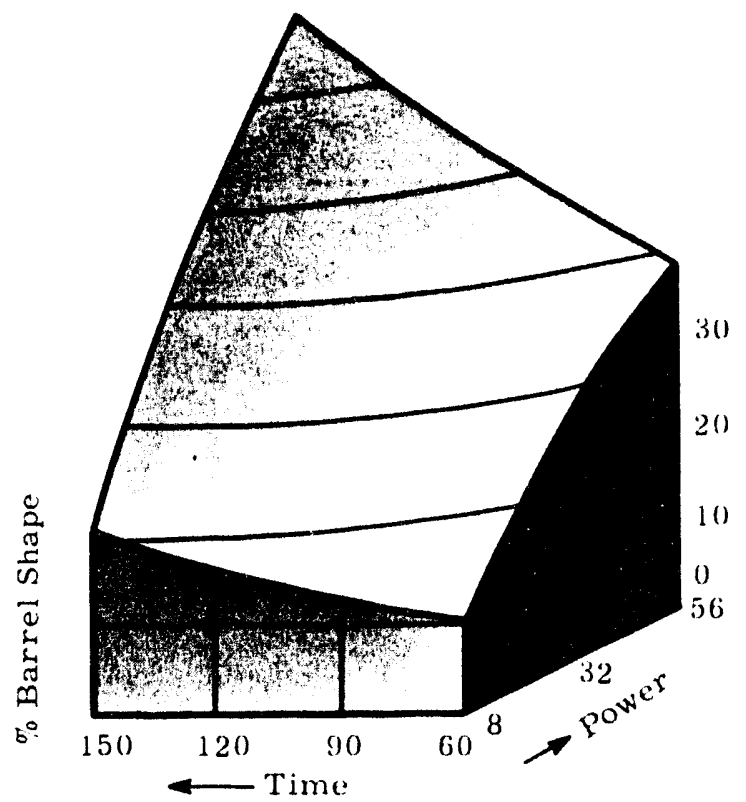

Response Surface for Per Cent Barrel Shape at $65^{\circ} \mathrm{C}$

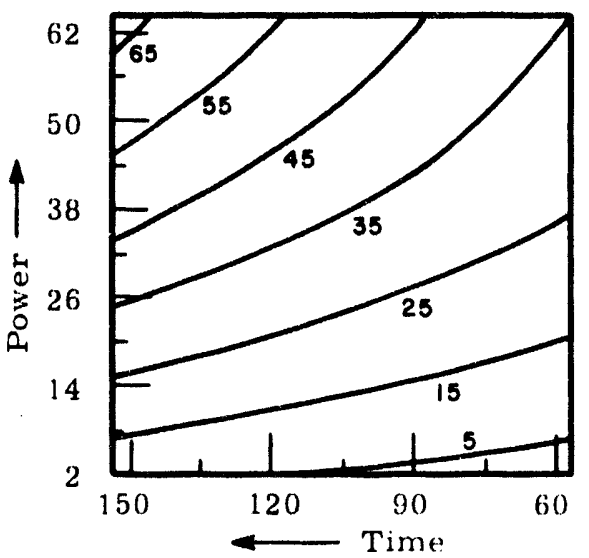

$\%$ Barrel Shape at $37^{\circ} \mathrm{C}$ and $93^{\circ} \mathrm{C}$

FIGURE 17

Effect of Power, Time, and Temperature on Percent Barrel Shape of Hanford I\& E Fuel Elements 


\section{$-40-$ \\ DECLASSIFIED}

6)

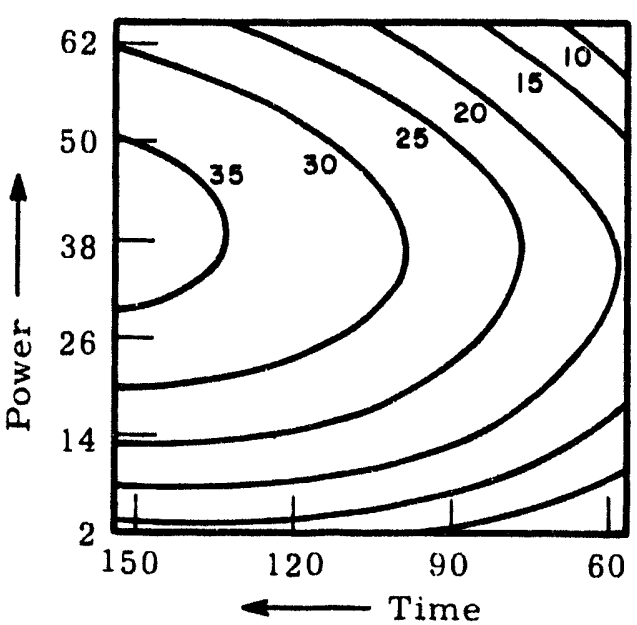

Temperature $=25^{\circ} \mathrm{C}$

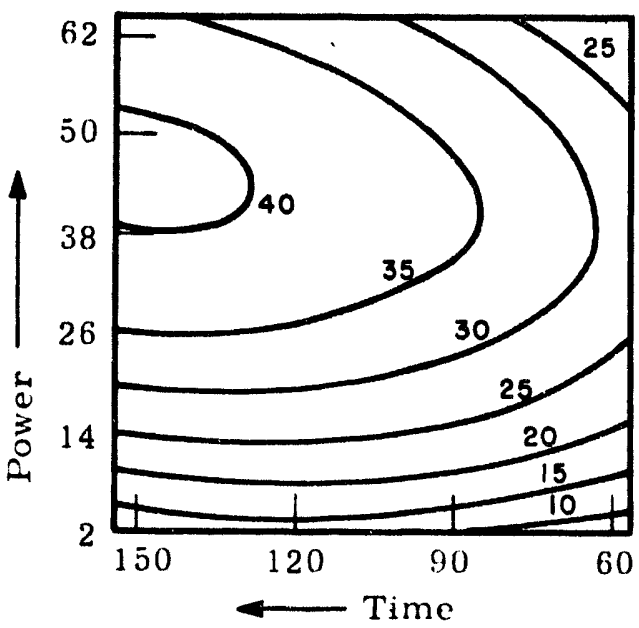

Temperature $=65^{\circ} \mathrm{C}$

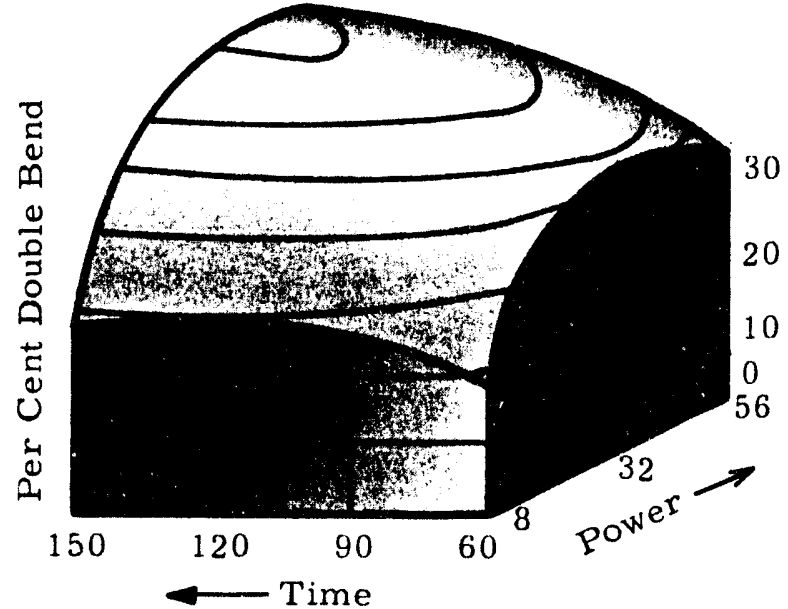

Response Surface for Per Cent Double Bend at $65^{\circ} \mathrm{C}$

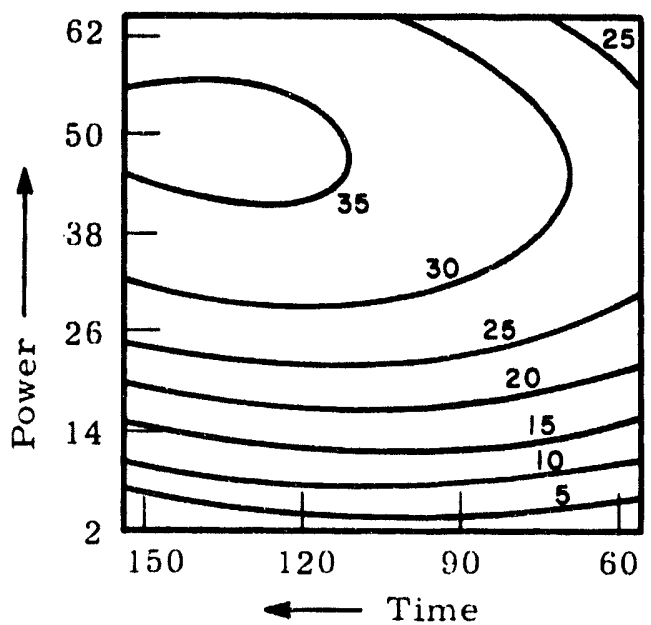

Temperature $=105^{\circ} \mathrm{C}$

FIGURE 18

Effect of Power, Time, and Temperature on Percent Double Bend of Hanford I\& E Fuel Elements 

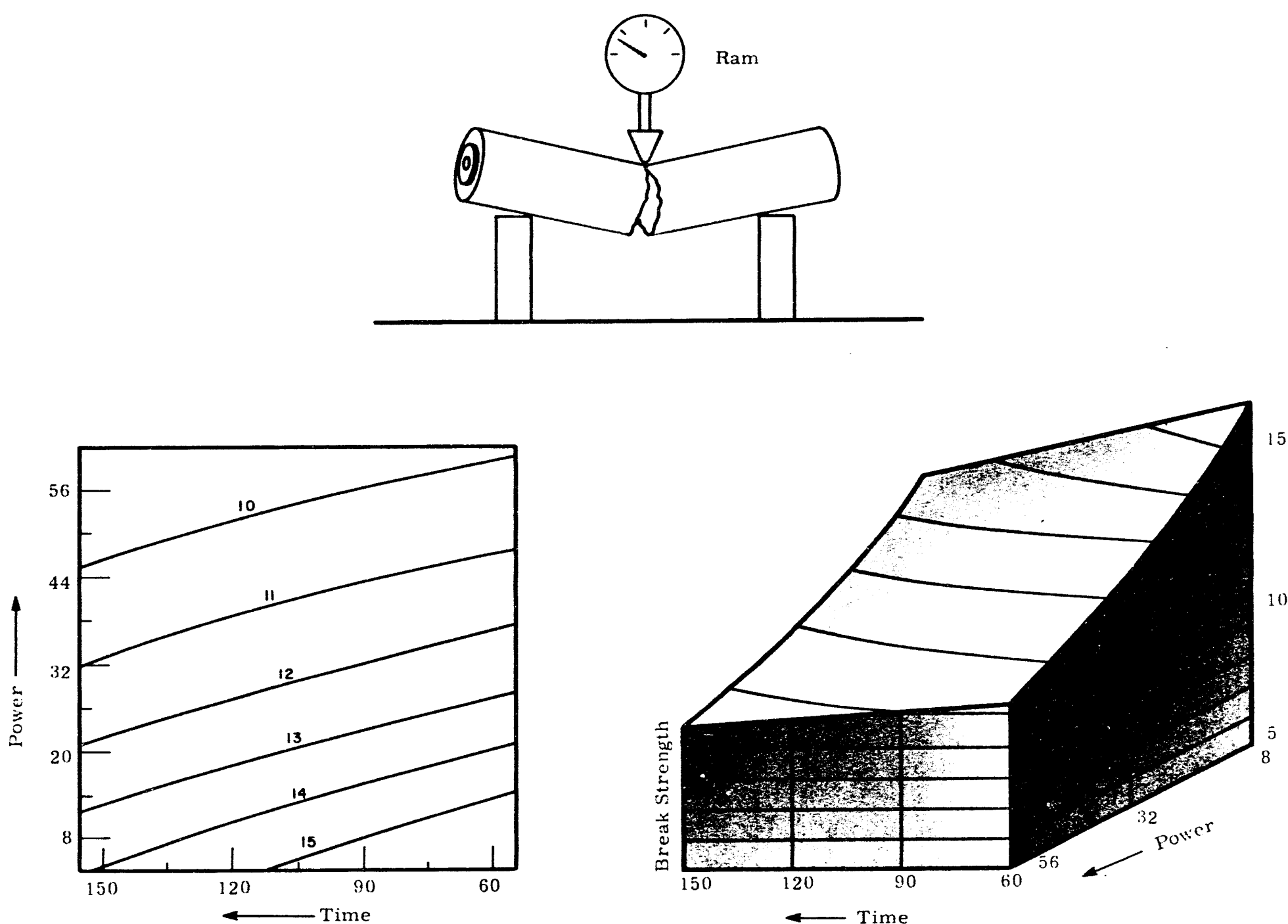

Break Strength Contour in Tons of Force

Response Strface for Break Strength

FIGURE 19

Effect of Power and Time on Break Strength of Hanford I\&E Fuel Elements 
3. Because TFC, $\triangle \mathrm{OD}_{2}$ and "Percent Barrel Shape" are influenced by temperature, calibration curves are shown on Figures 14, 16, and 17. With TFC as an example, contour lines can be found for any temperature by use of the temperature calibration curve. Three points have been selected below to illustrate.

\section{TABLE IV}

TEMPERATURE CORRECTION FACTORS FOR TFC

\section{Temperature of Interest}

$25 \mathrm{C}$

$65 \mathrm{C}$

$105 \mathrm{C}$
Correction

$-0.12$

$+0.14$

$-0.16$

\section{COMPARISON OF PREVIOUS AND REVISED MODELS}

In a comparison of the previous and revised models, examinations of the complete response surfaces of each would be of interest. Such a comparison is difficult to visualize. An illustration of the agreement between models can be given, however, by restricting the comparison to one independent variable at a time while holding the other variables at their average values.

These comparisons are shown in Figures 20 through 24. These figures illustrate that the differences between models are small.

The greatest discrepancies between models is for Warp and $\Delta \mathrm{OD}_{2}$. It will be noted from Figures 20 and 23 that the displacements of the curves are quite large. This is due to a decrease in Warp and an increase in $\Delta \mathrm{OD}_{2}$ for fuel elements measured during the past year and included in the new models. Note that the relative effects of the reactor variables remain the same, with only the intercept parameters changing. As pointed out in the section on Derivation of Models, this is of little concern. 

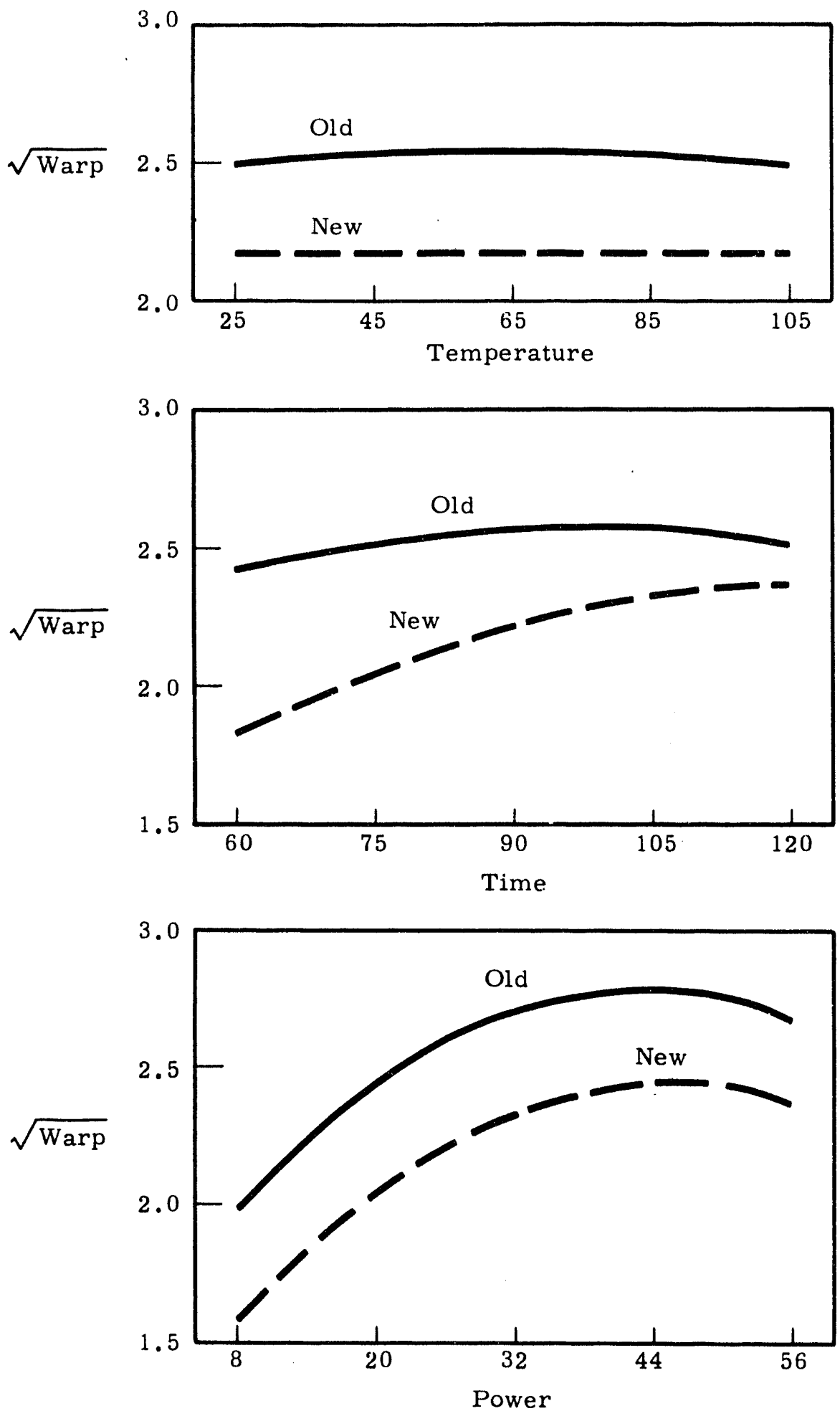

FIGURE 20

Comparison of Warp Models 

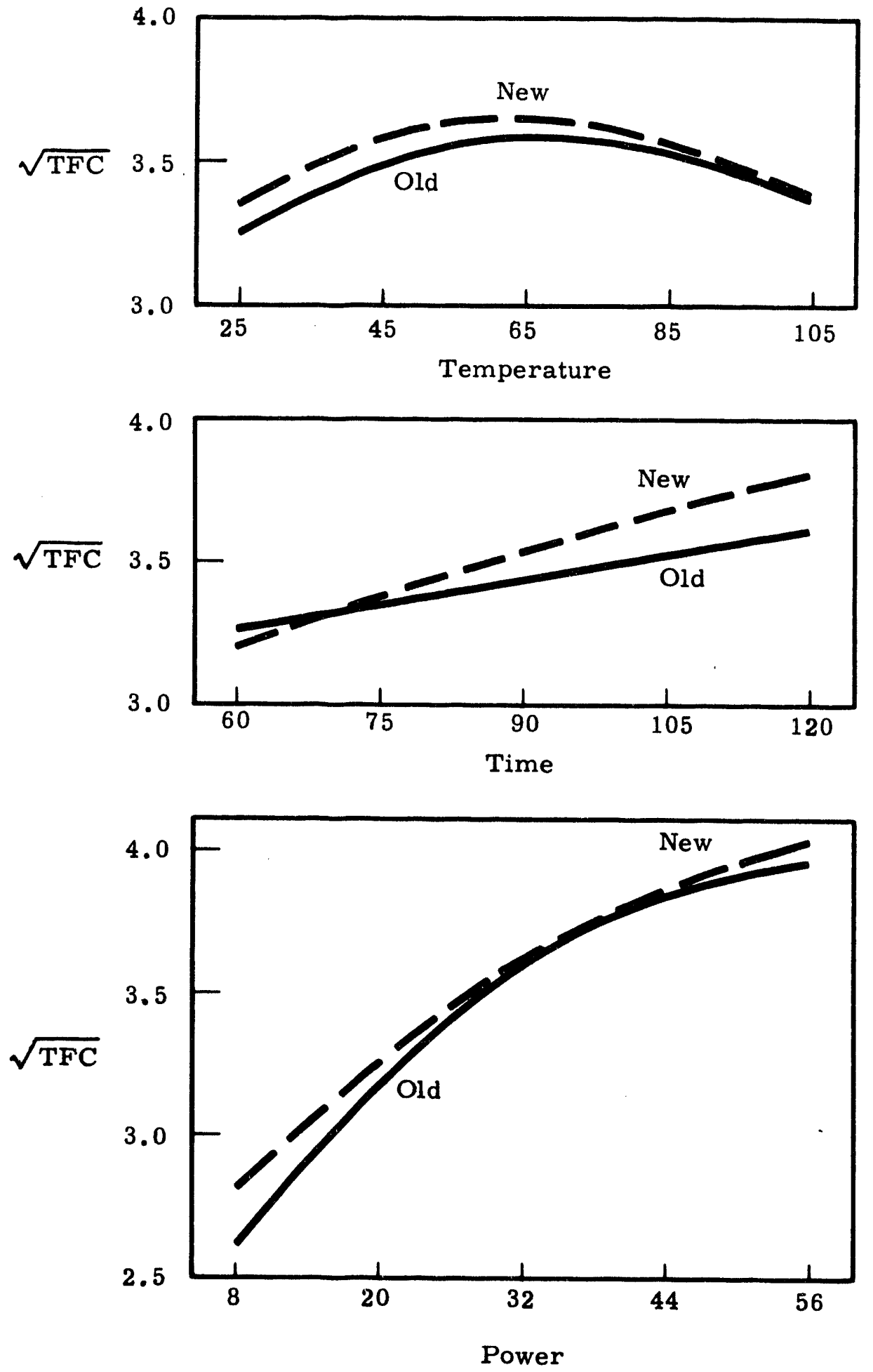

FIGURE 21

Comparison of TFC Models 

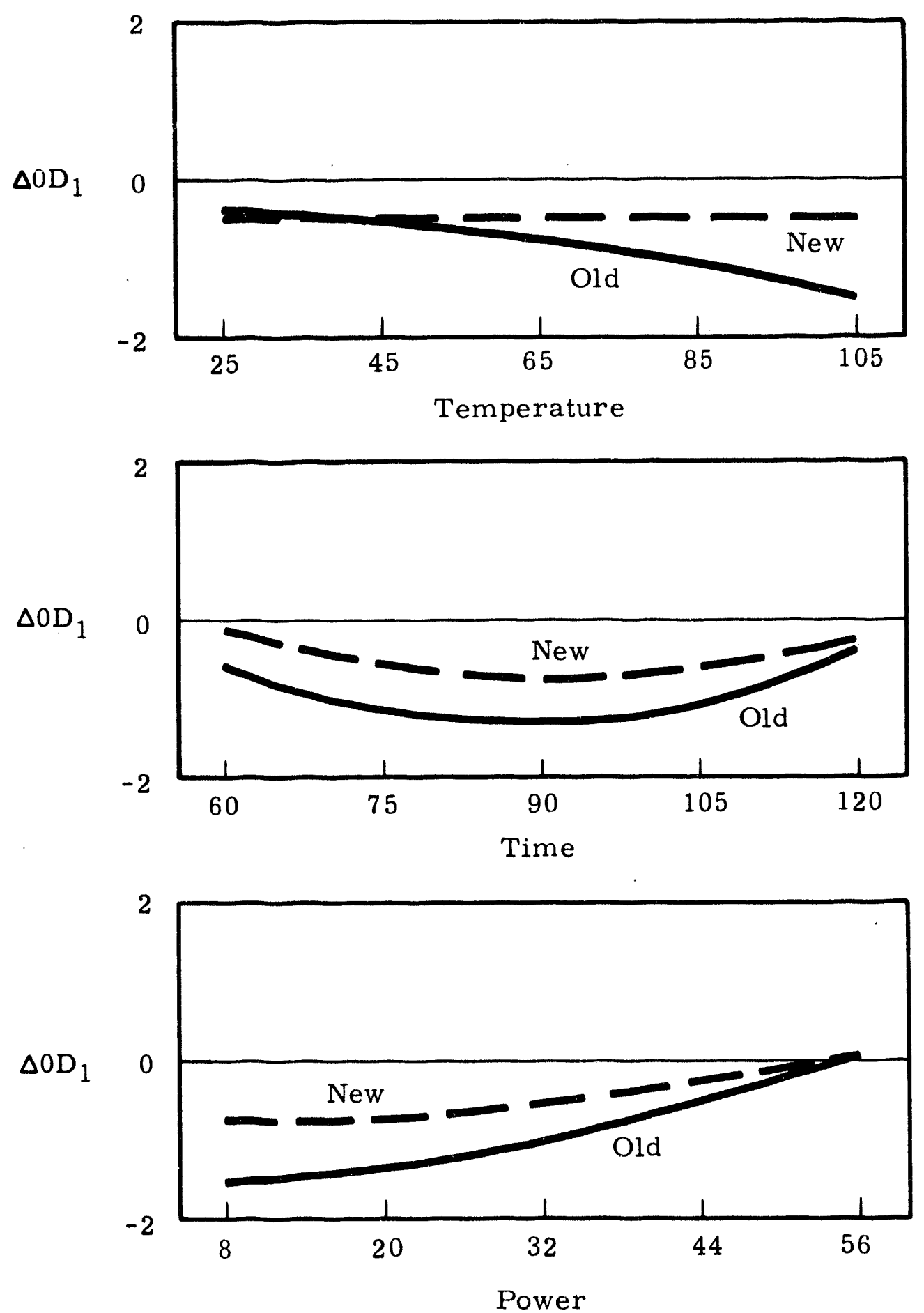

FIGURE 22

Comparison of $\triangle \mathrm{OD}_{1}$ Models 

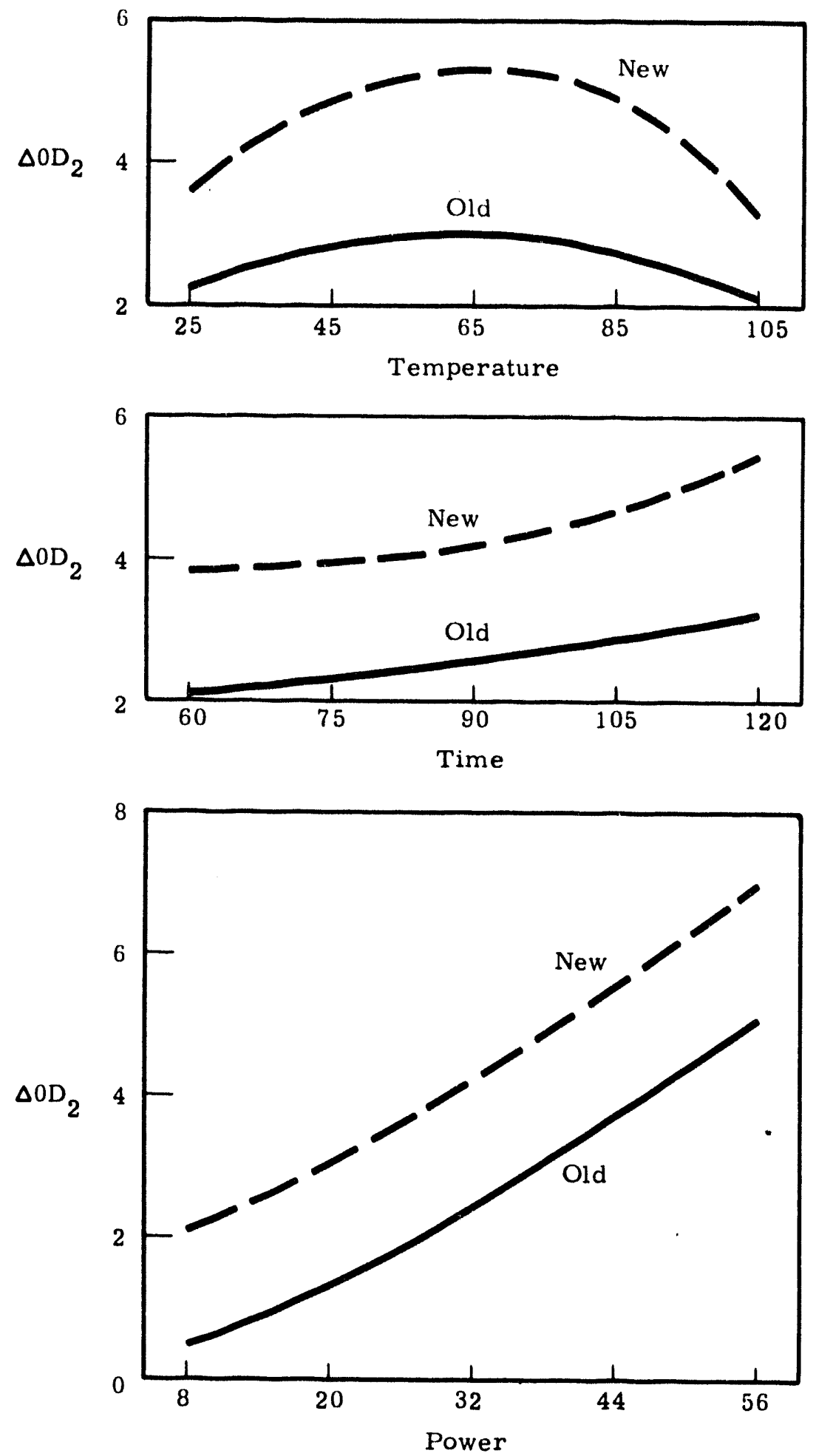

FIGURE 23

Comparison of $\triangle \mathrm{OD}_{2}$ Models 

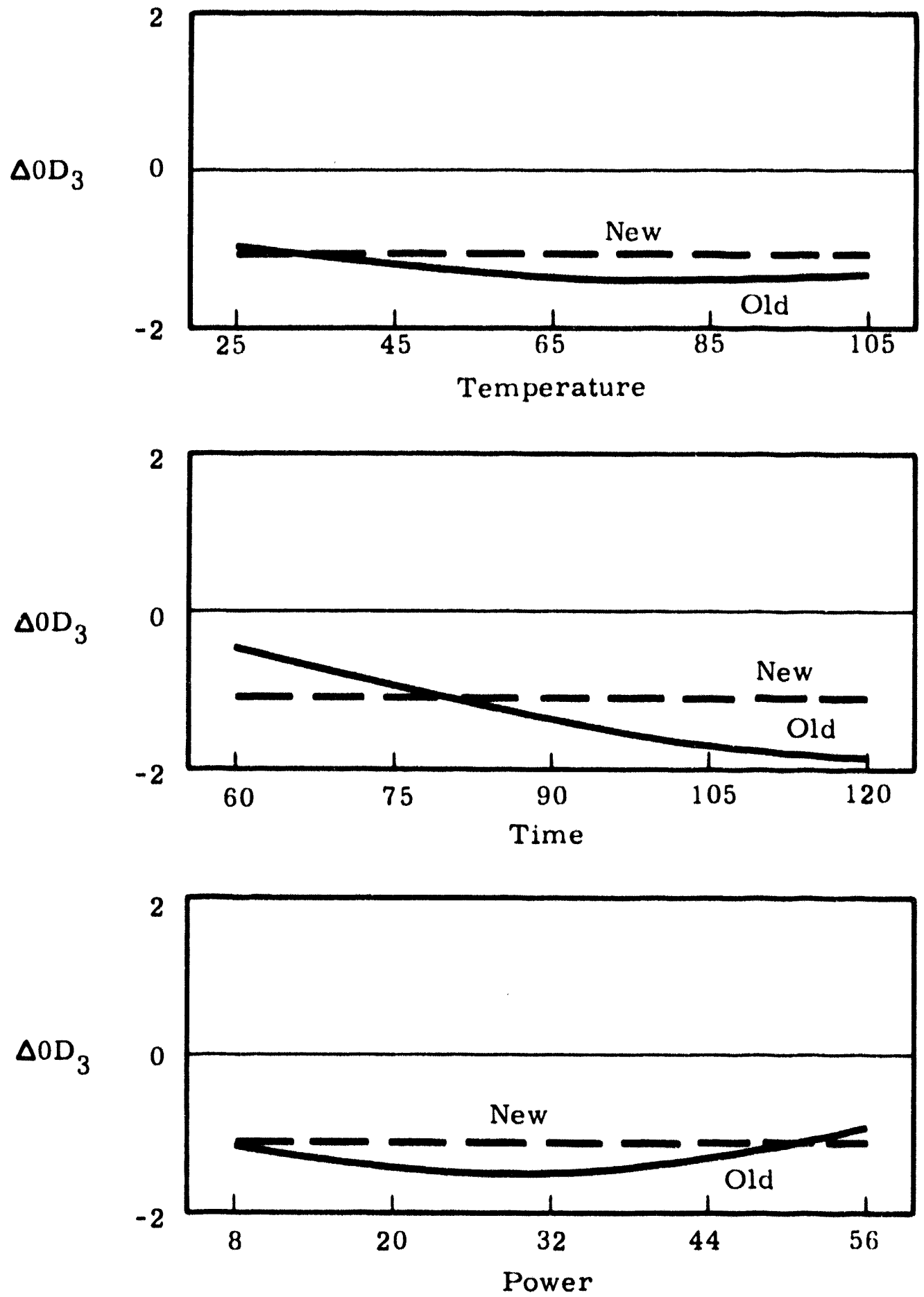

FIGURE 24

Comparison of $\triangle \mathrm{OD}_{3}$ Models 
In view of the agreement between previous and revised models, it is doubtful if further model development will be required for some time.

\section{APPLICATION OF MODELS}

Mathematical models relating fuel performance to irradiation conditions within the Hanford reactors have been used for study of fuel variables since the initial development early in 1960. Not until large amounts of data from the Quality Certification Program began to accumulate could reactor effects be quantified.

Conclusions Based on Information Given by the Models

1. The results of the Quality Certification Program have demonstrated that ir radiation performance for normal production fuel elements is not constant. This fact has established the need to explain why differences occur.

2. Irradiation-induced changes are large enough to influence both the operation of a reactor and fuel element design.

\section{Uses of the Models}

1. Since Quality Certification monitor charges can involve materials of special interest, more direct methods of comparing such materials are now possible by use of the models. Such comparisons are clear!y not as good as would result from a well controlled production test. However, it is not possible to test everything in specially designed production tests.

2. The models permit greater flexibility in the design of production tests because the "block" size can be increased now that effects of reactor power and temperature differences within a process tube can be removed.

3. With recognition of inherent dangers in the extrapolation of empirical models, these models can be used to predict distortion for a group of fuel elements irradiated under a specified set of reactor conditions. 


\section{FUTURE PROGRAMS}

This report points out that the models were developed with specific applications in mind. The fact that good correlations were found despite the seemingly large variability in postirradiation dimensional data confirms the original hypothesis that there are identifiable reasons for this variation. The effects of variables associated with reactor environment have now been removed by the models. Now that there is a much better identification of the fuel element variables in a monitor charge, there is reason to believe that much of this additional variation will be removed. Once this is accomplished, but not before, the "knowledge-producing" aspects of the Quality Certification Program will have been completed.

The following programs are under way.

1. Monitor charges irradiated under the Quality Certification Program are being identified on the basis of primary castings. This action results in more homogeneous material within a charge, and will permit relating fuel performance to primary casting characteristics.

2. The uranium production centers are transmitting quantities of fabrication data to Hanford under the Feed Site Uranium Data Processing Program. This information will be used to evaluate performance of the monitor charges. Without this information, the identification of uranium variables would be impossible.

3. Greater emphasis is being given to assure the accuracy and precision of fuel measurements.

4. The useful information derived from the Quality Certification Program has demonstrated the need for comparable information on the New Production Reactor fuel elements. To achieve this, a data processing system which contains the history of each fuel element throughout the entire production stream is under development. 


\section{ACKNOWLEDGEMENTS}

The information contained in this report represents the combined efforts of many people. The authors gratefully acknowledge the assistance of all who contributed to this in some way. Of special note is the contribution of R. D. Gillette of Hanford's Electronic Data Processing Operation who developed most of the data processing systems necessary for this work. The importance of his contribution cannot be minimized. We also acknowledge the assistance of B. B. Vinson of the Hanford Laboratories who developed the generalized least squares linear regression routine used in developing the mathematical models. The editing efforts of Flora F. Spencer are also gratefully appreciated.

\section{REFERENCES}

1. Hagie, L. T. A Customer-Vendor Quality Certification Program for Fuel Elements, HW-58454. December 8, 1958. (CONFIDENTIAL).

2. Fouts, J. M. Post-Irradiation Fuel Element Examination Data, HW-64590 REV3. March 3, 1961.

3. Jaech, J. L. Describing Fuel Element Distortion Using Orthogonal Polynomials, HW-70643. August 4, 1961.

4. Hagie, L. T. and J. L. Jaech. Analysis of Quality Certification Data Warp, TFC and $\Delta \mathrm{OD}_{2}$ as a Function of Reactor Operating Conditions, HW-67530. November 23, 1960. (SECRET).

5. Hagie, L. T. Computer Utilization in Evaluating Fuel Performance, HW-73875. (To be published). 


\section{BIBLIOGRAPHY}

Hagie, L. T. Machine Processing of Fuel Element Examination Data, HW-66536. August 18, 1960 .

Hagie, L. T. Quality Certification Data (Summary of Dimensional Characteristics from 5-26-59 to 1-25-60), HW-64147. March 3, 1960.

Hagie, L. T. and J. L. Jaech. Analysis of Quality Certification Data - Effects of Warp on the Incidence of Hot Spots, HW-67120. October 14, 1960 .

Hagie, L. T. and J. L. Jaech. Fuel Element Statistics from the Quality Certification Program, HW-72322. January 16, 1962.

Jaech, J. L. Use of Statistics in Fuel Element Performance Studies at Hanford, HW-SA-2253. August 10, 1961 . 


\section{INTERNAL DISTRIBUTION}

\section{Copy Number}

$\begin{aligned} 1 & \text { F. W. Albaugh } \\ 2 & \text { T. W. Ambrose } \\ 3 & \text { E. R. Astley } \\ 4 & \text { R. S. Bell } \\ 5 & \text { C. A. Bennett } \\ 6 & \text { H. E. Berg } \\ 7 & \text { W. A. Blanton } \\ 8 & \text { A. G. Blasewitz } \\ 9 & \text { R. R. Bloomstrand } \\ 10 & \text { J. H. Brown } \\ 11 & \text { R. J. Bursey } \\ 12 & \text { S. H. Bush } \\ 13 & \text { J. J. Cadwell } \\ 14 & \text { A. C. Callen } \\ 15 & \text { Z. E. Carey } \\ 16 & \text { J. R. Carrell } \\ 17 & \text { M. A. Clinton } \\ 18 & \text { D. L. Cornell } \\ 19 & \text { R. L. Dickeman } \\ 20 & \text { E. A. Evans } \\ 21 & \text { T. W. Evans } \\ 22 & \text { W. J. Ferguson } \\ 23 & \text { E. J. Filip } \\ 24 & \text { G. C. Fullmer } \\ 25 & \text { S. M. Gill } \\ 26 & \text { R. D. Gillette } \\ 27 & \text { S. M. Graves } \\ 28 & \text { O. H. Greager } \\ 29 & \text { A. B. Greninger } \\ 30 & \text { C. N. Gross } \\ 31 & \text { W. J. Gruber } \\ 32 & \text { A. E. Guay } \\ 33 & \text { L. T. Hagie } \\ 34 & \text { G. L. Hammons } \\ 35 & \text { G. R. Hanson } \\ 36 & \text { C. M. Heeb } \\ 37 & \text { W. H. Hodgson } \\ 38 & \text { C. G. Hough } \\ 39 & \text { J. L. Jaech } \\ 40 & \text { R. T. Jessen } \\ 41 & \text { F. W. Knight } \\ 42 & \text { L. E. Kusler } \\ 43 & \text { L. W. Lang } \\ 44 & \text { G. A. Last } \\ 45 & \text { C. G. Lewis } \\ & \end{aligned}$




$\begin{array}{ll}46 & \text { A. R. Maguire } \\ 47 & \text { W. M. Mathis } \\ 48 & \text { J. E. Minor } \\ 49 & \text { W. N. Mobley } \\ 50 & \text { H. C. Money } \\ 51 & \text { T. D. Naylor } \\ 52 & \text { J. W. Nickolaus } \\ 53 & \text { R. Nilson } \\ 54 & \text { K. W. Norwood } \\ 55 & \text { R. E. Olson } \\ 56 & \text { H. M. Parker } \\ 57 & \text { R. S. Paul } \\ 58 & \text { C. A. Priode } \\ 59 & \text { T. Prudich } \\ 60 & \text { R. W. Reid } \\ 61 & \text { O. C. Schroeder } \\ 62 & \text { C. H. Shaw } \\ 63 & \text { R. D. Shimer } \\ 64 & \text { S. H. Small } \\ 65 & \text { R. B. Socky } \\ 66 & \text { H. G. Spencer } \\ 67 & \text { W. F. Stevenson } \\ 68 & \text { K. B. Stewart } \\ 69 & \text { J. T. Stringer } \\ 70 & \text { R. Teats } \\ 71 & \text { R. E. Trumble } \\ 72 & \text { F. W. Van Wormer } \\ 73 & \text { E. A. Weakley } \\ 74 & \text { W. W. Windsheimer } \\ 75 & \text { F. W. Woodfield } \\ 76 & \text { W. K. Woods } \\ 77 & \text { D. C. Worlton } \\ 78 & \text { Technical Publications } \\ 79 & \text { Record Center } \\ 80 & \text { 300 File } \\ 81-100 & \text { Extra } \\ & \end{array}$

\section{EXTERNAL DISTRIBUTION}

$101-102$

103

104

105
Atomic Energy Commission, Washington Atomic Energy Commission, Washington Attn: W. Devine, Division of Reactor Development Atomic Energy Commission, Washington Attn: F. R. Dowling Division of Reactor Development Chicago Patent Group 
106-109

110

111

112

113

114

115

116

117

118

119

120

121

$122-146$
duPont Company, Aiken duPont Company, Aiken Attn: L. V. Bailey duPont Company, Aiken Attn: T. C. Evans duPont Company, Aiken Attn: V: I. Montenyohl duPont Company, Wilmington Hanford Operations Office Hanford Operations Office Attn: A: T. Gifford Hanford Operations Office Attn: P. M. Midkiff Hanford Operations Office Attn: C. L. Karl

Cincinnati Area Office Office of the Assistant General Council for Patents (AEC)

Savannah River Operations Office Savannah River Operations Office Attn: J. W. Croach

Savannah River Operations Office Attn: P. J. Hagelston

Division of Technical Information Extension 

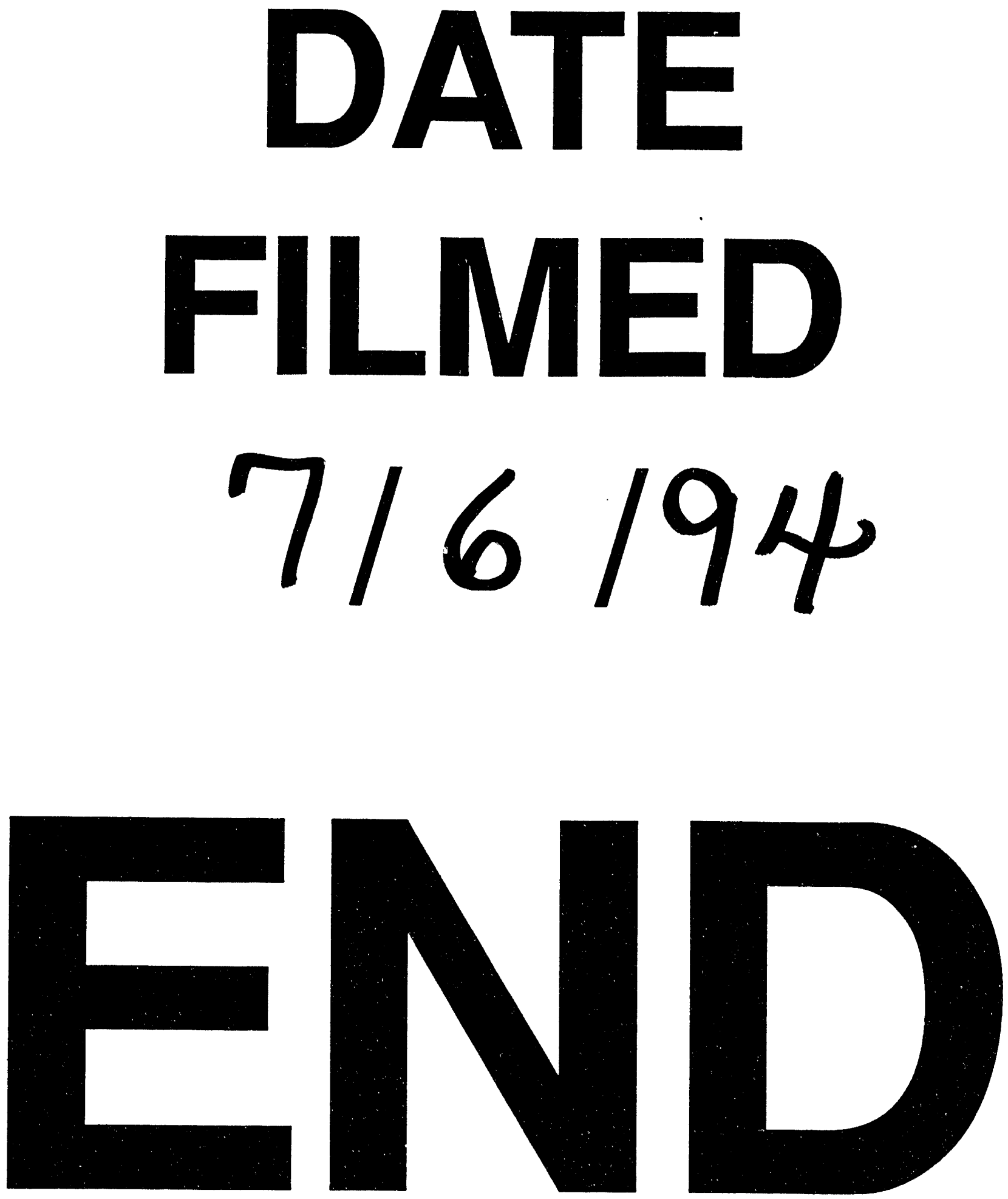
